LA-8610-MS

UC-41

Issued: December 1980

\title{
Oxidation of Depleted Uranium Penetrators and Aerosol Dispersal at High Temperatures
}

\author{
J. C. Elder \\ M. C. Tinkle
}

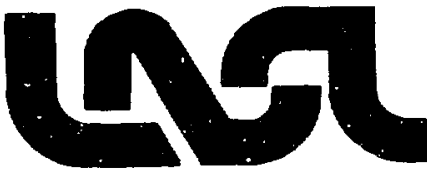




\section{CONTENTS}

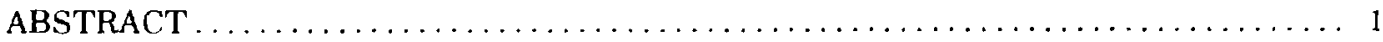

I. INTRODUCTION $\ldots \ldots \ldots \ldots \ldots \ldots \ldots \ldots \ldots \ldots \ldots \ldots \ldots \ldots \ldots \ldots \ldots \ldots \ldots$

11. EXPERIMENTAL APPARATUS AND TECHNIQUES $\ldots \ldots \ldots \ldots \ldots \ldots \ldots \ldots 2$

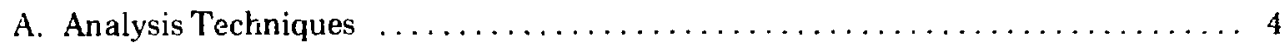

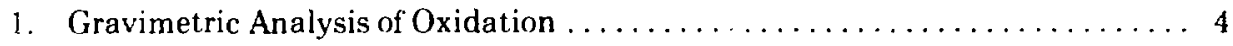

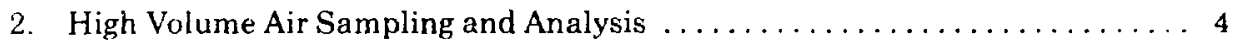

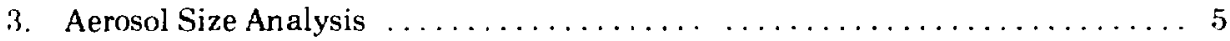

4. Particle Sizing by Sieving and Sedimentation $\ldots \ldots \ldots \ldots \ldots \ldots \ldots \ldots$

B. Outdoor Burn Tests . . . . . . . . . . . . . . . . . . . 6

C. Laboratory Oxidation and Aerosol Experiments ................. 7

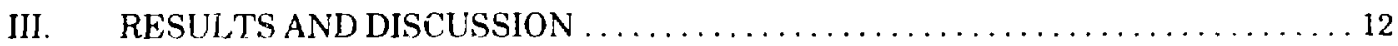

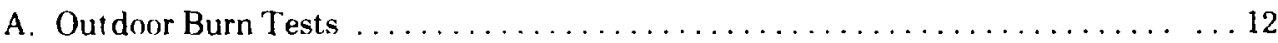

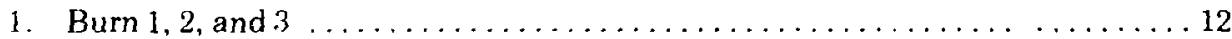

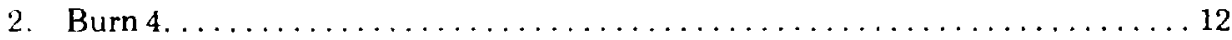

B. Laboratory Oxidation and Aerosol Experiments .................. 18

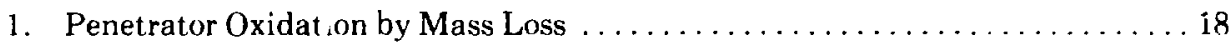

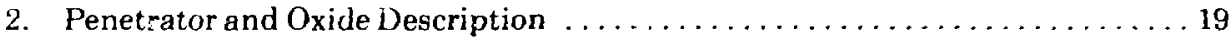

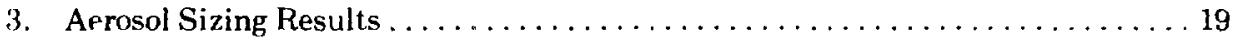

4. Effects of Temperature Change During the Run $\ldots \ldots \ldots \ldots \ldots \ldots \ldots \ldots \ldots$

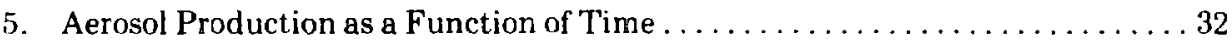

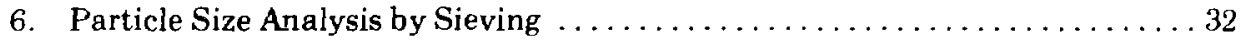

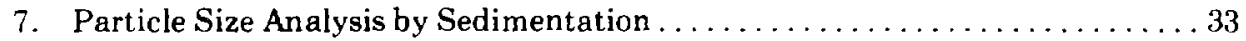

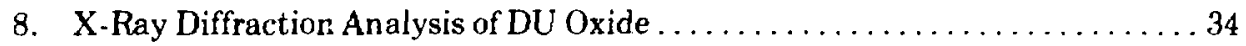

9. Scanning Electron Microscopy (SEM) of DU Oxide $\ldots \ldots \ldots \ldots \ldots \ldots \ldots$

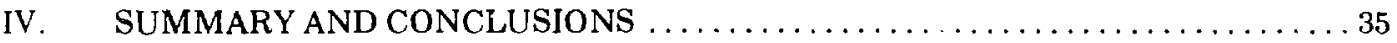

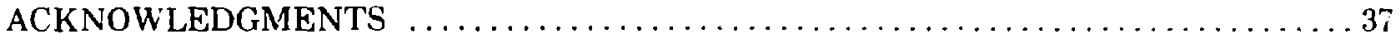

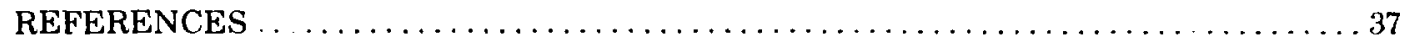

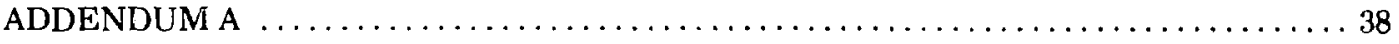

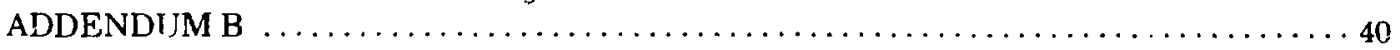




\title{
OXIDATION OF DEPLETED LRANIUM PENETRATORS \\ AND AEROSOL DISPERSAL AT HIGH TEMPERATURES
}

by

\author{
J. C. Elder and M. C. Tinkle
}

\begin{abstract}
Aerosols dispersed from depleted uranium penetrators exposed to air and air- $\mathrm{CO}_{2}$ mixtures at temperatures ranging from 500 to $1000^{\circ} \mathrm{C}$ for $2-$ or $4-\mathrm{h}$ periods were characterized. These experiments indicated dispersal of low concentrations of aerosols in the respirable size range |typically $<10^{-3} \%$ of penetrator mass at $223 \mathrm{~cm} / \mathrm{s}(5 \mathrm{mph})$ windspeed $\}$. Oxidation was maximum at $700^{\circ} \mathrm{C}$ in air and $800^{\circ} \mathrm{C}$ in $50 \%$ air $-50 \% \mathrm{CO}_{2}$, indicating some self-protection developed at higher temperatures. No evidence of self-sustained burning was observed, although complete oxidation can be expected in fires significantly exceeding $4 \mathrm{~h}$, the longest exposure of this series. An outdoor burning experiment using 10 batches of pine wood and paper packing material as fuel caused the highest oxidation rate, probably accelerated by disruption of the oxide layer accompanying broad temperature fluctuation as each fuel batch was added.
\end{abstract}

\section{INTRODUCTION}

This report describes a series of experiments requested by the U.S. Army Armament Research and Development Command (ARRADCOM) and performed jointly by Groups H-5 (Industrial Hygiene) and CMB-8 (Physical Chemistry and Metallurgy) of Los Alamos Scientific Laboratory (LASL). The primary purpose of the experiments was to characterize the nature ard amount of uranium particles dispersed if depleted uranium (DU) metal penetrators in anti-tank munitions (designated XM774) were slibjected to fire in a storage depot or during iransport. Nornal storage condition for DU munitions is within a large covered bunker (igloo) in the presence of excess air, soft pine wood storage boxes, paper-base packing tubes, and artillery propellant within the shell casings. These materials are all combustible. Uranium is a pyrophoric material but sustains burning only in finely divided form, that is, dispersed small fragments or fine turrings. ${ }^{1}$ Since published data were limited on the dispersion of aerosols from large DU metal rods similar to the 
penetrators, these experiments were initiated to simulate, in semi-controlled conditions, the exposure of the penetrators to high temperature, oxidizing at mosphere, and an intermediate wind speed of $223 \mathrm{~m} / \mathrm{s}(5 \mathrm{mph})$.

The first phase of these experiments consisted of three simplified outdoor burn tests in which burning DL turnings or artillery propellant provided the heat source. The second phase consisted of laboratory experiments in which penetrators were exposed to temperat ures from 500 to $1000^{\circ} \mathrm{C}$. (all under the $1132^{\circ} \mathrm{C}$ theoretical melting point of DU metal) in a tube furnace under dynamic flow conditions of air or an air $-\mathrm{CO}_{2}$ mixture. The third phase consisted of a prolonged outdoor burn within a wind tunnel apparat us. The heat source was the combustion of soft pine wood and paper packing tube material in a 2.5 to 1 ratio by weight to simulate packing conditions of the X.MTi4 round. The determination of characteristics of DU aerosols under violent conditions such as combined wood fire and rapid propellant burning by which penetrators could be displaced into or out of high temperature regions was considered beyond the scope of this test series.

Coleman and Schwendiman ${ }^{2}$ investigated particulate release from 0.69 . by $1.9-6 \mathrm{~m}$ long uranium cylicters at furnace temperatures from 400 to $1200^{\circ} \mathrm{C}$. They observed a general increase in oxide particle size with increasing temperature. Less than $4 \%$ of the oxide formed was in the $<10-\mu \mathrm{m}$ aerodynamic equivalent diameter $\left(\mathrm{D}_{\mathrm{ur}}\right)$ particle size range in any of the cases they investigated. The air velocit ies over the cylinders were $8.3,3.3 .2$, and $66.4 \mathrm{~cm} / \mathrm{s}$ ( significantly lower than the 22:3 cm/s suggested by ARRADCOM for our study). Effect of air velocity on the aerodynamic entrainment of uranium oxide particles was not clearly deduced in the referenced study, although the authors expected air velocity effects to be more significant in entraining the smaller particles formed at lower temperaiures $\left(400-800^{\circ} \mathrm{C}\right)$. The specimens generally remained int act until significant temperature change occurred to cause flaking during thermal cont raction.

In another study, Megaw, et al. ${ }^{3}$ oxidized one kilogram uranium slugs at temperatures up (0) 100()$^{\circ} \mathrm{C}$ in air and pure $\mathrm{CO}_{2}$. Air velocities ranged from 85 to $260 \mathrm{~cm} / \mathrm{s}$. Increasing particle size with increasing temperature was observed, as in the Coleman experiment. Average particle size decreased with increasing velocity, probably indicative of some breaking up of oxide particles by increasing turbulence. In the Megaw experi. ¿nt. the specimens were heated in a high frequency eddy current furnace rat her than by heating coils external to the furnace. A sharp increase in oxidation rate was noted between 750 and $80^{\prime} 1^{\circ} \mathrm{C}$ and was attributed to beta-gamma phase transition at $771^{\circ} \mathrm{C}$. Slightly higher oxidation rates occurred in pure $\mathrm{CO}_{2}$ than in air.

\section{EXPERIMENTAL APPARATUS AND TECHNIQUES}

The XM7T4 penetrator is shown in Fig. 1. This pointed rod is $34.5-\mathrm{cm}$ iong, $2.59-\mathrm{cm}$ nominal diameter, and weighs $3355 \pm 3 \mathrm{~g}$. Its surfaces are smoot hexcept for the $12.7-\mathrm{cm}$ section of buttress grooves (2.94-cm maximum diameter, $2.59-\mathrm{cm}$ minimum diameter) located approximately midway and the $2.1-\mathrm{cm}$ threaded length on one end. In its normal storage and deployment configuration, the penetrator is covered by a thin aluminum windscreen and a thicker three-piece aluminum sabot which joins the penetrator to the shell casing and an aluminum tail fin threaded onto the rear of the penetrator. None of the experiments described here employed the aluminum pieces to evaluate the fire protection the aluminum might offer the penetrator. Aluminum melts at approximately $650^{\circ} \mathrm{C}$ and would only offer protection to a penetrator at the periphery of a fire.

Techniques used to evaluate oxidation and measure particle size characteristics were consistent among the various experiments and are described below. In general, exposure $t$ m selected as follows:

(1) Fuel was expended, concluding the burn test;

(2) 2 -h run time was arbitrarily selected in the early laboratory experiments as producing a desired effect on the penetrator; and 


$$
1
$$


(3) 4-h runs were conducted in the later laboratory runs at DARCOM request.

The $22: 3 \mathrm{~cm} / \mathrm{s}(5 \mathrm{mph})$ gas velocity was selecied as a reasonable compromise between the two extremes of nowind and heavy wind. In all the experiments the $223 \mathrm{~cm} / \mathrm{s}$ velocity was provided at the plane immediat ely ahead of the penetrator. In all cases, some change in gas velocity occurred due to the presence of the penetrator and fuel and support structures causing reduced crosssectional area in the flow channel. These changes were not investigated.

Vone of the experimental conditions was expected to produce an oxygen-deficient atmosphere. Half' of the laboratory experiments were conducted using $50 \%$ air- $50 \% \mathrm{CO}_{2}$ to simulate an atmosphere containing a combustion product but this was by no means a reducing at mosphere.

\section{A. Analysis Techniques}

1. Gravimetric Analysis of Oxidation. Penetrators were cleaned and weighed befre each experiment on a Mettler beam balance capable of weighing $4 \mathrm{~kg}$ within $\pm 0.1 \mathrm{~g}$. After exposure, each penetrator was cleaned by light mechanical work and motor-driven wire brushing. The penet rator was then weighed on the same balance to determine the oxidation of metal caused by the exprosure. Mass balances were performed in the laboratory experiments by separately weighing all oxide removed from the penetrator after the experiment. The penetrator was weighed after the light mechanical work. To account for the nonrecoverable oxide mass removed by brushing. the difference between this prebrushing penetrator weight and the post-brushing penetrator weight was multiplied by a stoichiometric factor of 1.1829 and added to the oxide weight to yield the (sital oxide mass. The factor of $: .1829$ is the theoretical conversion factor for the uraniumtitanium alloy reaction to $\mathrm{U}_{3} \mathrm{O}_{3}-\mathrm{TiO}_{2}$.

2. High Volume Air Sampling and Analysis. Mass crncentration of DU aerosol was determined by mass analysis of samples collected by high volume air samplers with flow rates up to $0.038 \mathrm{~m}^{3} / \mathrm{s}\left(80 \mathrm{ft}^{3} / \mathrm{min}\right)$. These samplers held a glass fiber filter [MSA1106BH (Mine Safety Applianccs. Pittshurgh, Pennsylvania)! nominally 20 by $25 \mathrm{~cm}(8 \mathrm{by} 10 \mathrm{in}$.) and were operated at various flow rates controlled by variable resistor on the blower motor. Gas flow rates were calibrated in advance by pitot tube traverses of the duct. The DU mass collected on each filter was determined by gamma counting nne-fourth of the filter with a 10 - by $10-\mathrm{cm}$ (4- by 4 -in.) thallium-drifted sodium iodide scintillation detector. Minimum letectable level of DU with this counter was $0.040 \pm 0.010 \mathrm{mg}$. Amounts smaller than $0.040 \mathrm{mg}$ were acid leached from the g! ass fiber filters using an $\mathrm{HCl}$ acid leach-ion exchange procedure (with about $40 \%$ recovery) $c$ nd submitted for separate analysis by delayed neutron counting technique. The acid leach removed collected DU and the ion exchange removed sodium which interfered with the delayed neutron counting analysis. Delayed neutron analysis requires the samples to be placed in a $25-\mathrm{cm}^{3}$ vial, exposed (1) a high thermal neutron flux, and counted for delayed neutrons produced from fission of the residual ${ }^{235} \mathrm{U}$ in 1 he DU. Minim um detectable level of DU by this method was $0.02 \mu \mathrm{g}$. $\left.\mathrm{MI}\right]$ standards were prepared for each set of samples.

The first sets of DU samples (Burns 1,2, and 3) were not successfully analyzed due to erroneous scaling of DU mass on the first samples. These samples were submitted for analysis by the method routinely used for urinalysis, which was scaled for much luwer concentrations, and werc disposed of after one count. Thereafter, special analysis procedures were initiated to prevent future mishandling of samples. 
3. Aerosol Size Analysis. Particle size characterization obtained during most of the experiments was obtained using one of two configurations of an inertial cascade impactor /Andersen eight-stage ambient sampler with $10-\mu \mathrm{m} \mathrm{D}_{\mathrm{ae}}$ precutter (Andersen Samplers, Inc., Atlanta, Georgia) |. Normal impactor sampling flow rate was $28.3 \mathrm{~L} / \mathrm{min}\left(1 \mathrm{ft}^{3} / \mathrm{min}\right)$ at ambient conditions (approximately $775 \mathrm{mb}$ and $20^{\circ} \mathrm{C}$ ). Effective cutoff diameters $\left(D_{50} \mathrm{~s}\right)$ for each stage in the two configurations were:

\begin{tabular}{cc}
\multicolumn{2}{c}{ Complete Impactor } \\
\hdashline Stage & $\mathbf{D}_{\mathbf{5 0}}(\boldsymbol{\mu} \mathbf{m})$ \\
\cline { 2 - 2 } Precutter & 10 \\
0 & 9 \\
i & 5.8 \\
2 & 4.7 \\
3 & 3.3 \\
4 & 2.1 \\
5 & 1.1 \\
6 & 0.7 \\
7 & 0.4
\end{tabular}

Backup filter

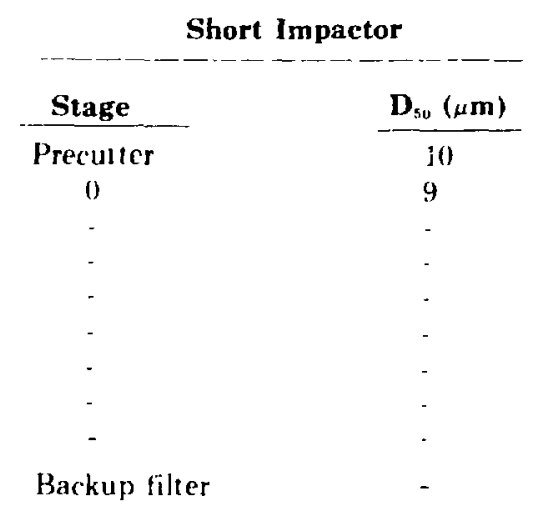

The short impactor provided $<10-\mu \mathrm{m}$ infor .1 ation with fewer samples. Stage 0 was included only to provide mechanical transition between the precutter and the backup filter. An 8.2 -cm glass fiber backup filter collected all particles passing the impactor stages.

Impactor mass data were analyzed by a computerized loast-squares curve fitting routine in which a lognormal distribution of particle aerodynamic dian eters was assumed. This distribution is described by two parameters, mass median aerodynamic diameter (mmad) and ger,metric standard deviation $\left(\sigma_{R}\right)$ The dat a analysis technique included only the stage masses (not the precutter mass) owing to the predominance of the precutter mass in most samples. Including the precutter mass as an additional stage of the impactor resulted in mmads larger than $20 \mu \mathrm{m}$. which was well beyond the meaningful range of the impactor. Separate reporting of the precutter mass and stage masses was considered more appropriate. Sample substrates covering the impaction plates were membrane filters [Millipore Type AA (Millipore Corporation. Bedford. Massachusetts)] throughout the laboratory experiments and in Burns 1, 2, and 3. Substrates were changed to glass fiber filters on inverted impaction plates to allow for heavier loading in Burn 4.

The effect of gas temperature on impactor calibration was not corrected for. owing to expected difficulty in measuring gas temperature at each impaction stage in each experiment. The maximum error in $\mathrm{D}_{\text {so }}$ (largest at the precutter and stage 0 ) would be proportional to (viscosity) ${ }^{12}$ where viscosity of air increases from 183 micropoises at $18^{\circ} \mathrm{C}$ (calibration temperature) to 211 micropoises at $75^{\circ} \mathrm{C}$ (estimated maximum at Stage 1 during the laboratory experiments). The maximum correction factor applied to the precutter and the first few impactor stages in this case would be approximately 1.07 or $<10 \%$ error in $D_{50}$, which is not significant in this instance.

Analysis of mass collected on impactor stages was initiated by screening each sample with the gamma counter. When the deposit was too small for gamma counting analysis, the sample was analyzed by delayed neutron counting, either directly if a membrane filter sample or after acid leaching and ion exchange if a glass fiber sample. Membrane filters were folded and deposited in $25 \mathrm{~cm}^{3}$ vials for delayed neutron counting analysis described earlier. 
4. Particle Sizing by Sieving and Sedimentation. The oxide inaterial collected from the tube furnace in the laboratory experiments was subjected to sieve analysis to separate size fractions down to U.S. Standard No. 400 sieve $(38 \mu \mathrm{m}) .^{5}$ The below 400 -sieve material was then subjected to sedimentation size analysis. The total oxide from each run was first sieved by hand on a U.S. Standard No. 12 sieve to remove very large pieces from the gross powder. Approximately $100 \mathrm{~g}$ of the DL oxide pa sing the No. 12 sieve was weighed to the closest $0.1 \mathrm{~g}$ and analyzed in a set of nested sieves of the U.S. Standard series No. 16, 20, 30, 40, 50, 70, 100, 140. 200. 270. and 400. A Tyler (W. S. Tyler. Inc., Mentor, Ohio) Ro-Tap shaker accommodated six standard sieves at a time. requiring two sieve runs for each analysis. The sieving time was $15 \mathrm{~min}$. The mass fractions retained by each sieve were weighed to the nearest $0.1 \mathrm{~g}$ and plotted as cumulative percent is mesh opening on Tyler Screen Scale diagrams. Midpoint $(50 \%)$ values from these plots provided an indication of central tendency, that is, a mass median diameter of nonairborne particles.

Particles passing through the U.S. Standard No. 400 sieve were submitted for size analysis by the Sartorius Sedibal method. ${ }^{6}$ This method records mass increase vs time on a micrubalance pan at the bottom of an ethylene glycol column. Oxide particles were prepared for analysis by ultrasonically agitating a suspension of $0.6 \mathrm{~g}$ oxide in ethylene glycol for $10 \mathrm{~min}$ to separate aggregated particles. The suspension was then introduced into the column and stirred. Mass settling on the microbalance was then recorded over appropriate time intervals. Sedimentation techniques describe the particle size characteristics of the batch powder in terms of Stokes diameter. which is the diameter of a sphere of the given density of the material which, in the same suspension media and force field, has the same terminal settling velocity. Stokes diameter (STK) can be converted to $\mathrm{D}_{\mathrm{ne}}$, the diameter of a unit density sphere with the same terminal settling rekcity in air. by multiplying by (particle density $x$ slip correction $)^{\prime 2}$. if the particle size of interest is larger than approximately $1.5-\mu \mathrm{m}$ geomet ric diameter. the slip correction is 1.0 and may be neglected in this conversion. As will be noted in describing the sedimentation results later in this report this conversion was applied to sedimentation results $i$. 'low comparison with impactor results.

\section{B. Outdoor Burn Tests}

The four burning experiments described in this report were conducted at R-Site, Los Alamns Scientific Laboratory, an unforested area used extensively over the past 25 years for experiments involving uranium. Background uranium was a potential problem in the first three burning experiments due to their pruximity to heavy soil contamination at firing points E-F. This experience prompted moving the Burn 4 apparatus to a paved, low background area nearby.

Burns 1,2, and 3 were simple preliminary experiments to determine if the penetrators could be ignited. The penet rators were exposed to heat under expeditious, yet descriptive conditions of oxidation in excess air. Figure 2 summarizes the conditions and general configuration of each burn test. Figures 3 and 4 show the arrangement of the Burn 2 apparat us, which differea from Burn 1 and 3 only in the airflow path through the fuel-penetrator stack. All effuent gas from the hood in Burns 1 and 2 passed through the high volume air sampler. Burn 3 permitted open burning of the propellant followed promptly by placement of hood and samplers. Burn 4 permitted release of the smoke plume to the atmosphere. Occasional samples of Burn 4 effluent taken isokinetically with gross filter and eight-stage impactor with precutter collected aerosol for particie size characterization.

Thermocouples were added to measure penetrator temperatures after Burn 1. Chromel-alumel thermocouples were installed on the Burn 2 and 3 apparatus. Temperatures of the Burn 4 penetrators were monitored by platinum-platinum-rhodium thermocouples attached to each penetrator. Each new batch of wood-paper fuel (10 total) was added to the furnace through a side 

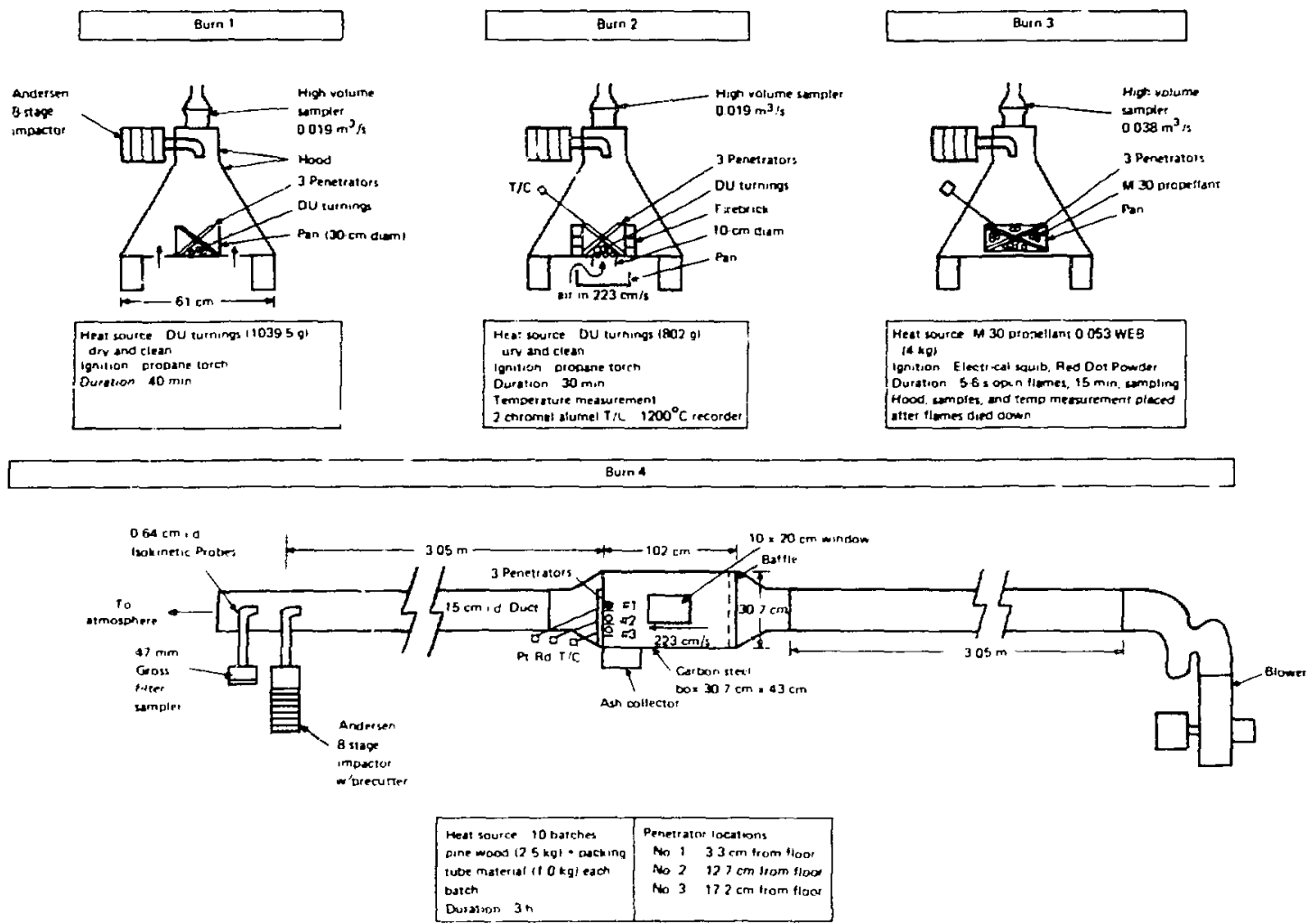

Fig. 2 .

Summary of outdoor burning experiments, general lavout.

port. The side port was normally closed by a Pyrex glass window which allowed observation of the fire. A view of the penetrators and furnace configuration is presented in Fig. 5 .

\section{Laboratory Oxidation and Aerosol Experiments}

The laboratory experiments were conducted at Wing 4, basement of the CMR Building, Los Alamos Scientific Laboratory. Production of uranium compounds and ot her activities involving uranium are routinely performed in this laboratory.

Arrangement of the tube furnace and air samplers used in the laboratory experiments is shown in Fig. 6. The tube furnace was a quartz tube $90-\mathrm{mm}$ i.d. and $122 \mathrm{~cm}$ in length. Each penet rator was located on the center line of the tube and was centered in the heat zone of the nichrome wire furnace. The penetrator was supported on two lavite (soap stone) pedestals that were $1.3-\mathrm{cm}$ wide, approximately $23 \mathrm{~cm}$ apart, and contacted the penetrator over a $1: 20^{\circ}$ arc. The pedestals were perforated with large holes to permit gas flow on the underside of the penetrator: however. some obstruction of gas flow probably occurred. A smaller support was located midway between the larger supports to limit sag of the penetrator at the higher temperatures.

The nose of the penetrator was usually pointed into the flow of gas; however, during the first three experiments the penetrator was positjoned with the blunt end pointing into the gas stream to allow insertion of a thermocouple $(\mathrm{T} / \mathrm{C} 2)$ into the $3-\mathrm{mm}$-diam hole at the ? lunt end of the 


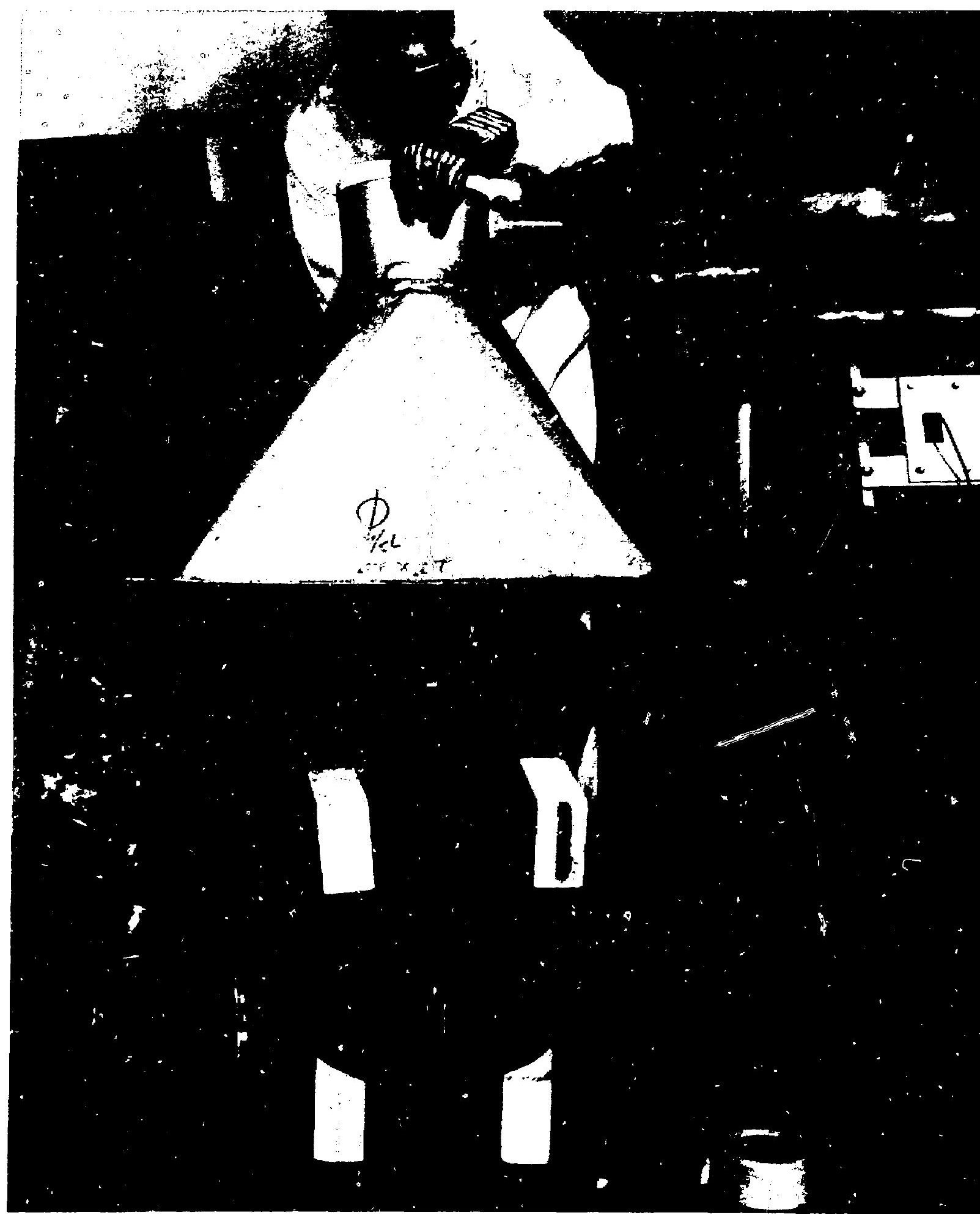

Fig. 3.

Burn 2 apparatus before assembly. 


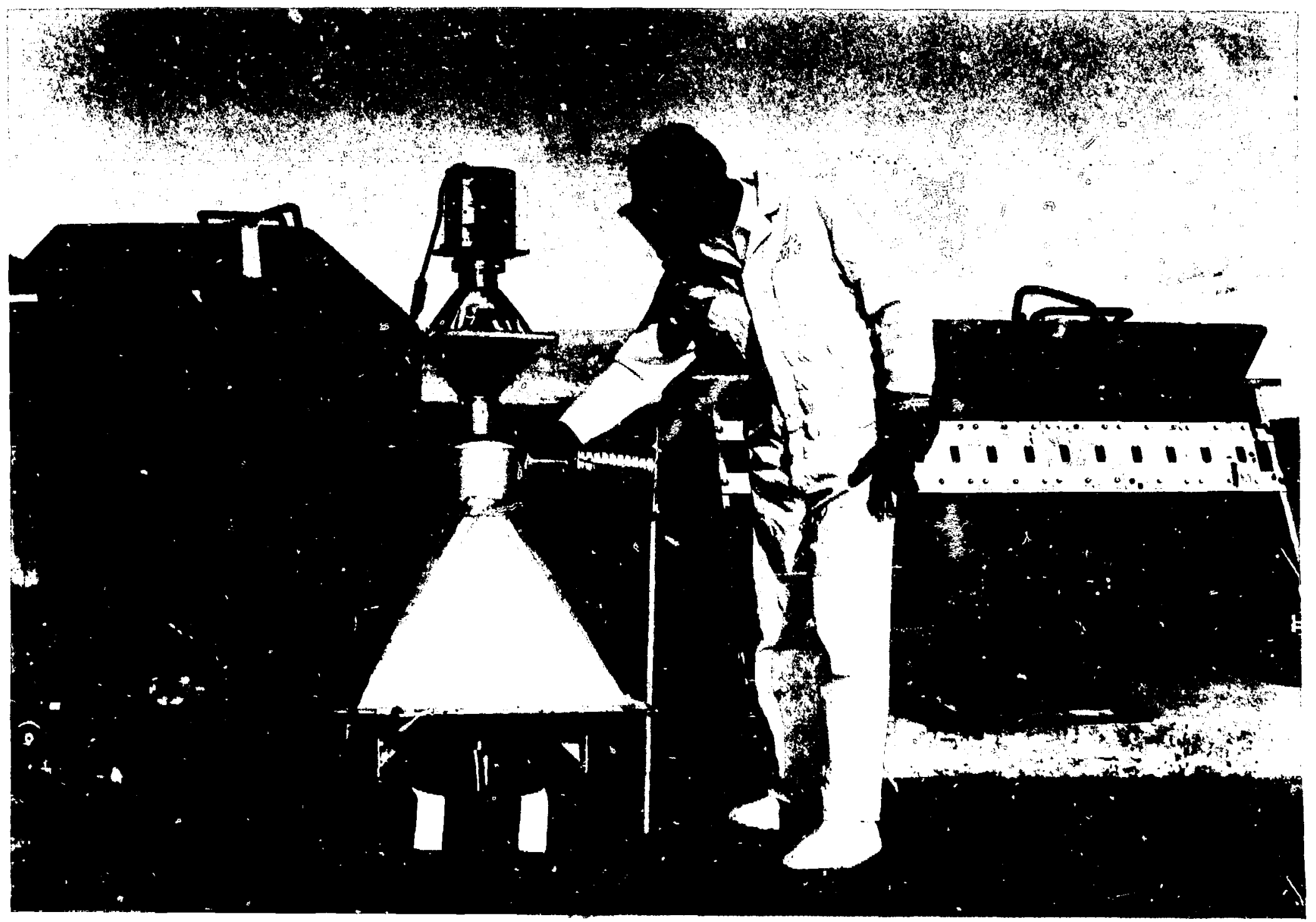

Fig. 4. 


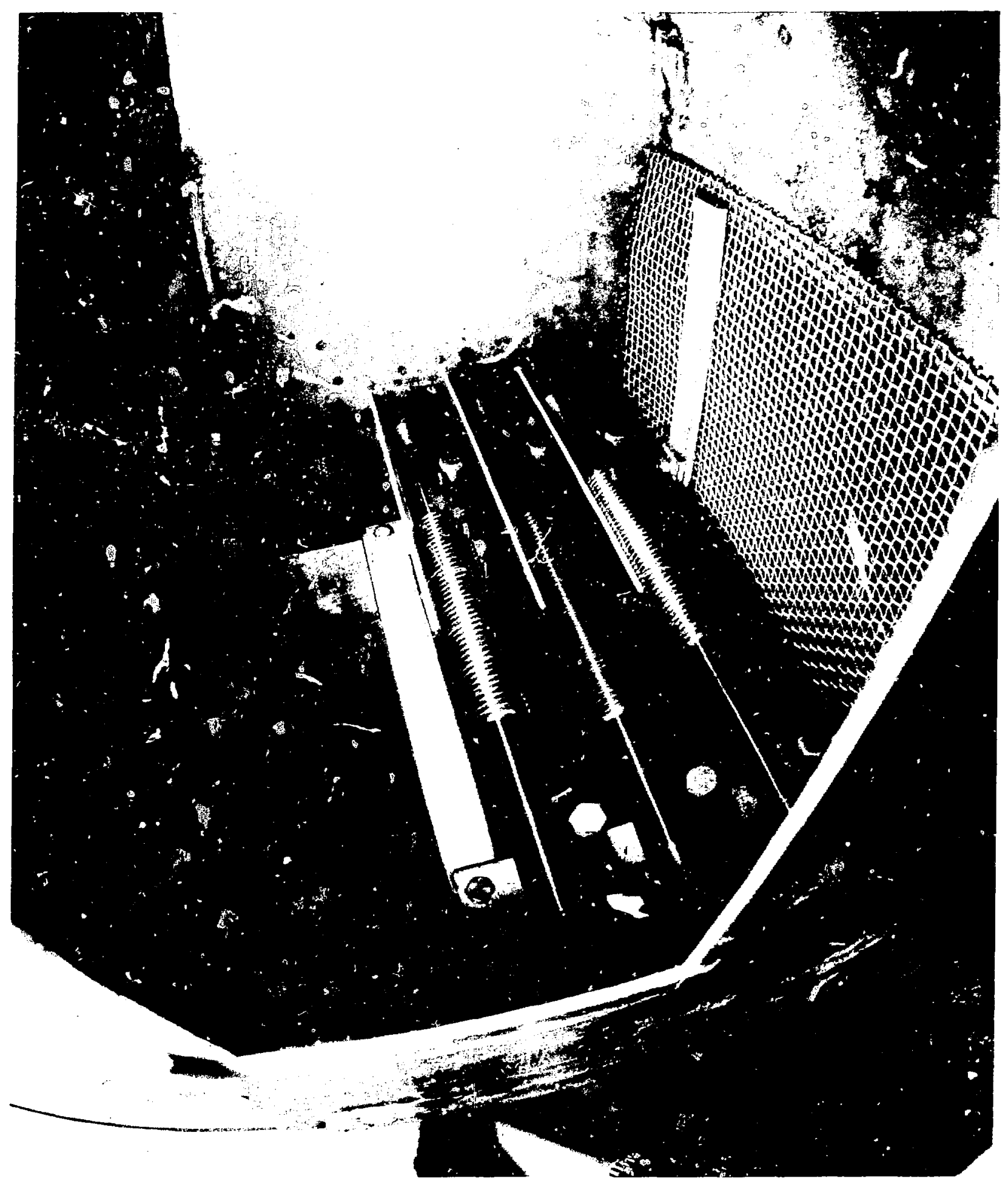

Fig. 5.

Interior setup of Burn 4 furnace box. 


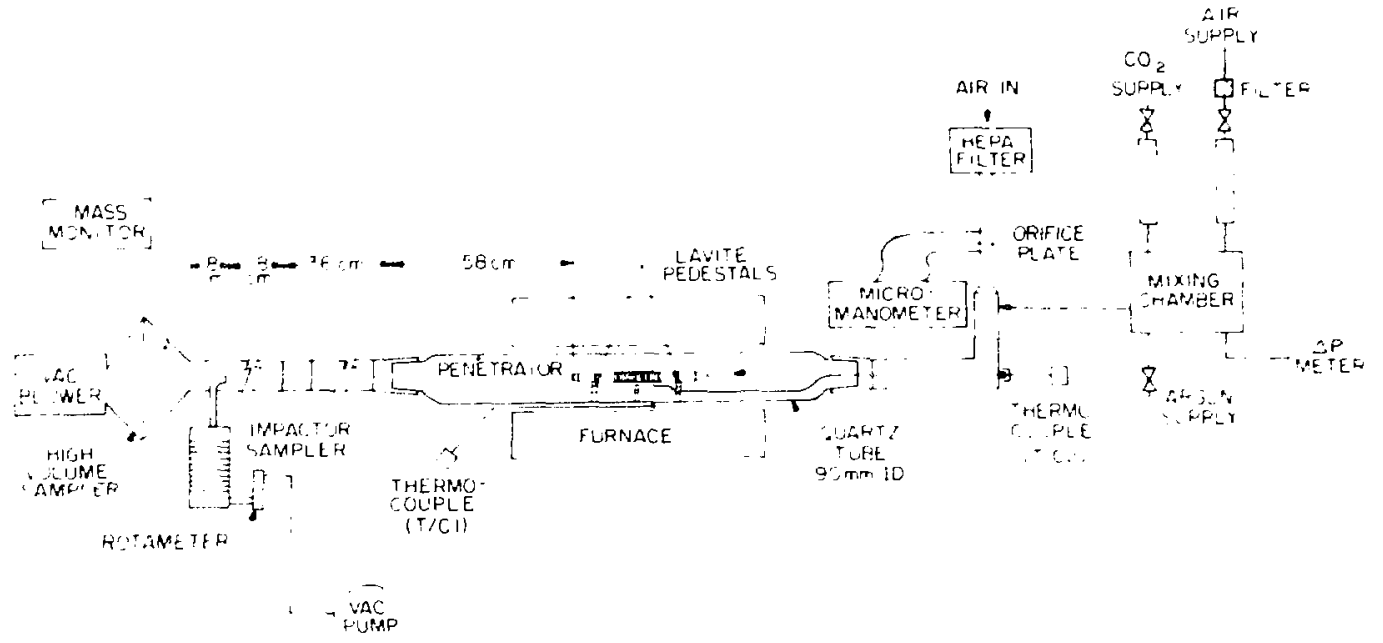

Fig. 6.

Laboratory experimental apparatus.

penetrator. When this proved unsatisfactory, the thermocouple was placed alongside the penetrator and the penetrator was reversed to direct its nose into the gas flow. Thermocouple $\mathrm{T} / \mathrm{C}$ 2 was placed in contact with the penetrator approximately $2.5 \mathrm{~cm}$ downstream of the first buttress groove. $\mathrm{T} / \mathrm{C} 2$ provided consistent indication early in the run but drifted later as oxide began to form on the penetrator, changing airflow around the thermocouple, or as the oxide sloughed off the penetrator, leaving the thermocouple more exposed to cooling. Therefore, data from T/C 2 during its stable period was used to determine the desired "nominal" temperature at its position; thereafter, T/C 1 controlled furnace temperature at the nominal temperature. Since incoming gas co. .ed the upstream end of the penetrator and caused a temperature gradient along its length, the nominal temperature should be considered an average temperature approximately $15 \mathrm{~cm}$ from the upstream end of the penetrator. Although total temperature gradient along the penetrator was not measured, it probably was as high as $100^{\circ} \mathrm{C}$ in the high temperature runs.

In all experimental runs using air as the oxidizing gas, room air was drawn through a highefficiency particulate air (HEPA) filter before entering the system. Airflow rate was determined by measuring the differential pressure across a calibrated sharp-edged orifice using a micromanometer. Gas flow of the air $-\mathrm{CO}_{2}$ mixtures was measured by rotameters calibrated against a dry test meter. The gas mixture was based on equal volumes of $\mathrm{CO}_{2}$ added from gas cylinders and filtered air added from the building compressed air system. These gas streams were mixed in a chamber and allowed to equilibrate at room temperature before being introduced into the tube furnace. Oxidation of the penetrator during heating and cooling periods was retarded by purging the tube furnace with argon gas.

A sample of the aerosol entrained in the gas stream downst ream of the penet rator was collected by an eight-stage Andersen impactor for particle size analysis. The remainder of the gas flow passed through a high volume sampler that provided primary suction for the test system. Flow through the high volume sampler raiged from 147 ambient $\mathrm{L} / \mathrm{m}$ in at lest conditions of $1000^{\circ} \mathrm{C}$ in the tube furnace to 242 ambient $\mathrm{L} / \mathrm{min}$ at $500^{\circ} \mathrm{C}$.

Air samples from each run submitted for DU mass analysis consisted of a glass fiber filter carrying the contents of the precutter; eight Millipore filter impactor stage substrates; the glass fiber backup filter; a 10- by 12 -cin glass fiber filter used to swipe the inlet tube to the high volume sampler; a similar swipe of the high volume sampler holder; and four quarters of the 20 - by 25 -cm high volume sampler filter. 
A (GCA portable respirable mass monitor (GCA/Technology Division, Bedford, Massachusetts) Model 101\%1, was connected by flexible tube to the high volume filter holder on 12 of 15 experimental runs to deiect the time of onset of aerosol production. Sampling flow rate for this instrument was only 2 ambient $\mathrm{L} / \mathrm{min}$, not $\in$ nough to interfere with the high volume sample. Sensitivits of the instrument was approximately $0.1 \mathrm{mg} / \mathrm{m}^{3}$. Only a qualitative indication of the presence of aerosol was expected from this instrument.

\section{RESULTS AND DISCUSSICN}

\section{A. Outdoor Burn Tests}

1. Burn I 2, and 3. Gravimetric analysis results of these preliminary burn tests are listed in Table I. Aerosol size characteristics data were not successfully obtained in these tests. Exposure of three penet rators to heat from burning uranium turnings in still air (Burn 1) caused negligible weight change or visually detectable surface change. Uranium from the turnings was recovered within (0.i) $\mathrm{g}$. The presence of aerosol was indicated only by light discoloration of the high volume sample.

Burn 2 results showed significant mass loss from all three penetrators (total $71.0 \mathrm{~g}$ ). The forced draft condition apparently caused significantly higher local heating. Although full time temperature measurements were attempted, thermocouples at the center of the $D L$ curnings bundle went off-scale at $1200^{\circ} \mathrm{C}$ within $5 \mathrm{~s}$ of ignition and remained off-scale until $5 \mathrm{~min}, 15 \mathrm{~s}$ into the burn. The 347 stainless steel sheath of one thermocouple melted near its tip; this metal melts at $1400-1425{ }^{\circ} \mathrm{C}$. Two of the three penetrators were slightly bent, indicating that some softening occurred. The melting point of pure uranium is $1132^{\circ} \mathrm{C}$, which is below the estimated maximum temperature for this run. However, the massive size of the penetrators and the lack of uniform heating over their full length probably preventerl general melting.

Burn 3 demonstrated that exposure of penetrators to a short, but intense fire did not have a significant effect as indicated by an observable surface change. Thermocouples and air samplers placed over the fire pan after propellant burnout indicated low temperature (approximately $100^{\circ} \mathrm{C} / 1 \mathrm{~min}$ after the propellant burn and little aerosol as indicated by slight discoloration of the high volume sample. This test might have been more descriptive if thermucouples of adequate range $\left(>1200^{\circ} \mathrm{C}\right)$ had been located in the propellant during the burn.

The general results of Burns 1,2, and 3 showrd (1) self-sustained burning of the penetrators did not occur, (2) oxidation of the penetrators occurred only in the forced-draft case (Burn 2), and (3) airborne material was produced in Burn 2.

2. Burn 4. The results of Burns 1, 2, and 3 led to further investigation of the forced-draft case in Burn 4. Direct exposure to the packing material fire, fanned by a $223 \mathrm{~cm} / \mathrm{s}(5 \mathrm{mph})$ wind for $3 \mathrm{~h}$ was expected to represent a severe exposure condition. Since conditions of time, temperature, and wind velocity in a storage fire have not been postulated, it can only be surmised that these test conditions equaled or exceeded those of a storage fire.

Temperature cycles between each of 10 batches of fuel ranged from 700 to $900^{\circ} \mathrm{C}$ (see chart records in Addendum A). T/C No. 1 on the $\mathrm{b}$ ttom penetrator was broken during installation and exhibited erratic performance. Highest temperatures were noted at the top penetrator (No. 3); $1100^{\circ} \mathrm{C}$ was exceeded during burning of 4 of the 10 batches.

Final penetrator weights after approximately $3 \mathrm{~h}$ exposure in the furnace box are shown in Table II. The middle penetrator was oxidized the most (47\%). The least oxidation occurred at the bottom penetrator $(42 \%)$, which was probably shielded somewhat by the ashes collected in the 
TABLE I

BURN 1, 2, AND 3

Gravimetric Results

\begin{tabular}{|c|c|c|c|c|c|c|}
\hline $\begin{array}{l}\text { Burn } \\
\text { No. }\end{array}$ & $\begin{array}{l}\text { Penetrati- } \\
\text { Serial No. }\end{array}$ & $\begin{array}{c}\text { Mass Before } \\
\text { Test (g) } \\
\end{array}$ & $\begin{array}{l}\text { Mass After } \\
\text { Test (g) }\end{array}$ & $\begin{array}{l}\text { Gain or } \\
\text { Loss (g) }\end{array}$ & \multirow{6}{*}{$\begin{array}{l}\text { Location } \\
\text { Top } \\
\text { Middle } \\
\text { Bottrn }\end{array}$} & \multirow{6}{*}{$\begin{array}{c}\text { Number } \\
3 \\
2 \\
1\end{array}$} \\
\hline 1 & f 059609 & 3354.0 & $3354.1 \mathrm{a}$ & +0.1 & & \\
\hline 1 & F059201 & 3355.5 & $3355.8^{\mathrm{a}}$ & +0.2 & & \\
\hline 1 & F045305 & 3354.0 & $3354.1^{\mathrm{a}}$ & +0.1 & & \\
\hline $\begin{array}{l}2 \\
2 \\
2\end{array}$ & $\begin{array}{l}F 059609 \\
F 059201 \\
F 045305\end{array}$ & $\begin{array}{l}3354.1 \\
3355.8 \\
3354.1\end{array}$ & $\begin{array}{l}3342.7^{a} \\
3336.2^{a} \\
3313.3^{a}\end{array}$ & $\begin{array}{l}-11.4 \\
-19.6 \\
-40.8\end{array}$ & & \\
\hline $\begin{array}{l}3 \\
3 \\
3\end{array}$ & $\begin{array}{l}\text { F045207 } \\
\text { FO4.221 } \\
\text { F045501 }\end{array}$ & $\begin{array}{l}3357.8 \\
3353.5 \\
3356.7\end{array}$ & $\begin{array}{l}3357.9 \mathrm{~b} \\
3353.8^{\mathrm{b}} \\
3356.8 \mathrm{~b}\end{array}$ & $\begin{array}{l}+0.1 \\
+0.3 \\
+0.1\end{array}$ & & \\
\hline
\end{tabular}

TABLE II

BUR' 4

Final Penetrator Weights

\begin{tabular}{|c|c|c|}
\hline $\begin{array}{l}\text { Serial } \\
\text { Number }\end{array}$ & $\begin{array}{l}\text { Final } \\
\text { Weight }(g)\end{array}$ & $\begin{array}{c}2 \\
\text { Oxide } \\
\text { (a of Origina? } \\
3355 \text { g Weignt })\end{array}$ \\
\hline $\begin{array}{l}045313 \\
045109 \\
04510 ?\end{array}$ & $\begin{array}{l}1874 \\
1772 \\
1947\end{array}$ & $\begin{array}{l}44 \\
47 \\
42\end{array}$ \\
\hline
\end{tabular}

dafter cleaning to bare meta?.

bafter scrubting with water to rencve $2-3 \mathrm{~g}$ propellant residue.

bottom of the box. These penetrators are shown in Fig. 7 with the oxide layers still intact after exposure. After removal from the furnace box the penetrators continued to oxiciize as they cooled, as shown in Fig. 8. The penetrators were cleaned by wire brushing to remove all oxidized material, as shown in Fig. 9. Each sagged noticeably between the two supports of the frame.

The relatively high loss of material from the penetrators in this $3-\mathrm{h}$ burn, $45 \%$ vs $25 \%$ on the average in the 4 -h lah runs $\left(700^{\circ} \mathrm{C}\right.$ and above from Table IV) probably resulted from rapid temperature fluctuations causing the protective oxide layer to break away and expose fresh metal surface to be oxidized.

Air sampling results from Burn 4 are summarized in Table III. Oxide mass concentrations in the tailpipe effluent ranged from $4.2 \mathrm{mg} / \mathrm{m}^{3}$ during Batch 1 to $782 \mathrm{mg} / \mathrm{m}^{3}$ during Batch 8 . These air samples were initiated after the new batch of fuel was actively rekindled ( 4 to 5 min after ${ }^{*}$ restart of the blower). Variation of mass concentration among the four samples is probably attributable to temperature cycles of $700-900^{\circ} \mathrm{C}$ in progress during the 5 -min sampling periods. Differential thermal expansion of the base metal with respect to the oxide layer could cause material to be dispersed, much of it small enough to remain airborne along the tailpipe. The air sampling periods were selected during periods when this material dispersal was probably maximum. Concentrations as high as $782 \mathrm{mg} / \mathrm{m}^{3}$ (plus some wood smoke) should have been visually detected as a plume. However, visible smoke occurred only briefly upon restart of the blower, a time when the samplers were not operating.

The weight percent associated with particles $<10 \mu \mathrm{m}$ listed in Table III ranged from 20 to $62 \%$. This indicates a high fraction of aerosol mass was in the size range where lung deposition can occur. The $20 \%<10-\mu \mathrm{m}$ mass result obtained during Batch 4 was the only sample obtained with all stages in the impactor and appears artifically low with respect to the other three results. Since flow calibrations were made for both impactor configurations and the proper flow rates presumably used, this difference cannot be readily explained. If the same higher flow setting had been erroneously used for all runs, the precutter-backup filter configuration of Batches 1,8 , and 10 would have sampled at $32.4 \mathrm{~L} / \mathrm{min}$ rather than $28 \mathrm{~L} / \mathrm{min}$, causing a sample volume $16 \%$ higher than expected and a precutter cutpoint shift downward of $<1 \mu \mathrm{m}$. This possible error is not large enough to account for the much wider discrepancy in the weight percent $<10 \mu \mathrm{m}$ from Batch 4 . 


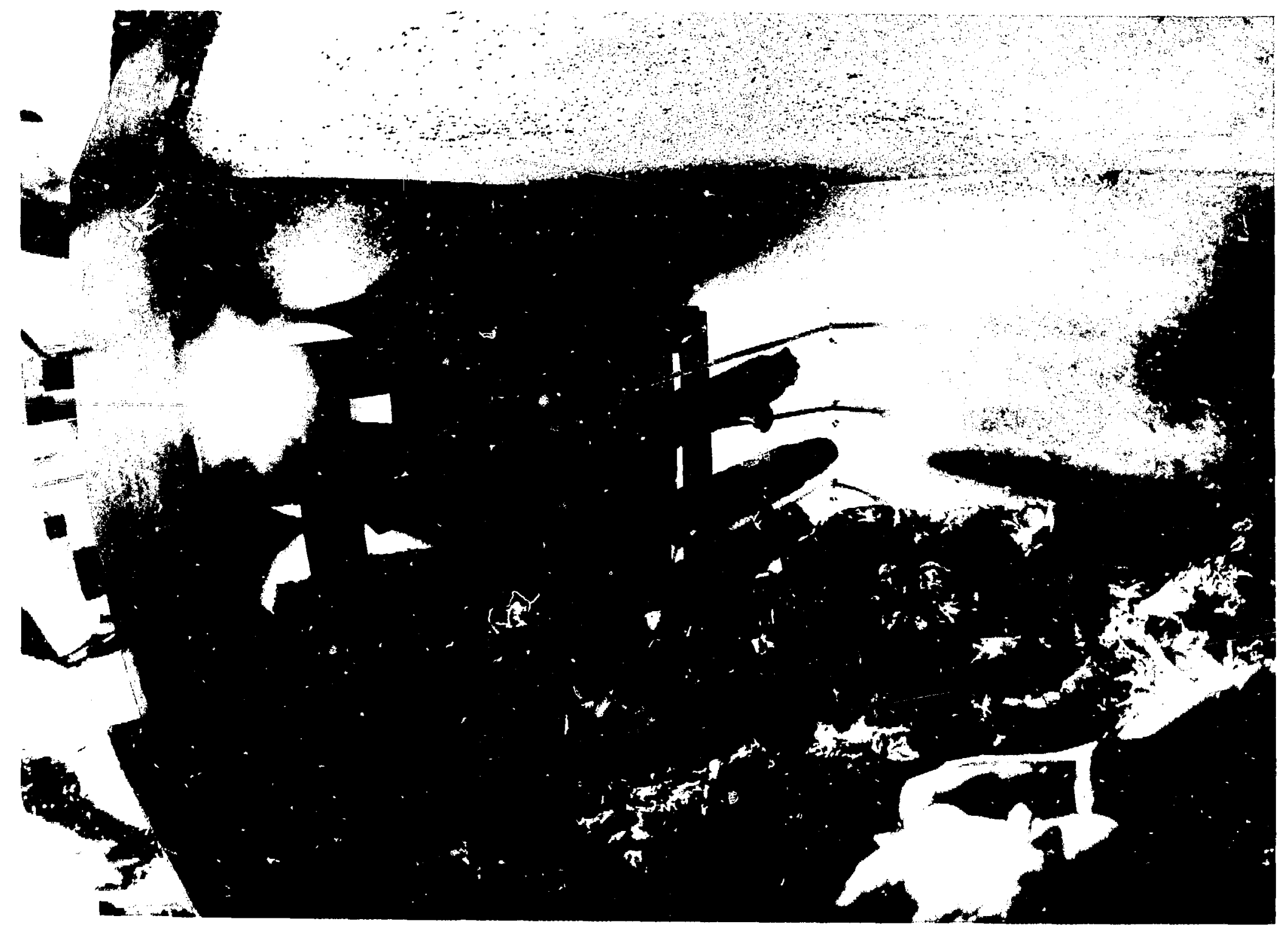

Fig. 7.

Penetrators and debris after Burn 4. 


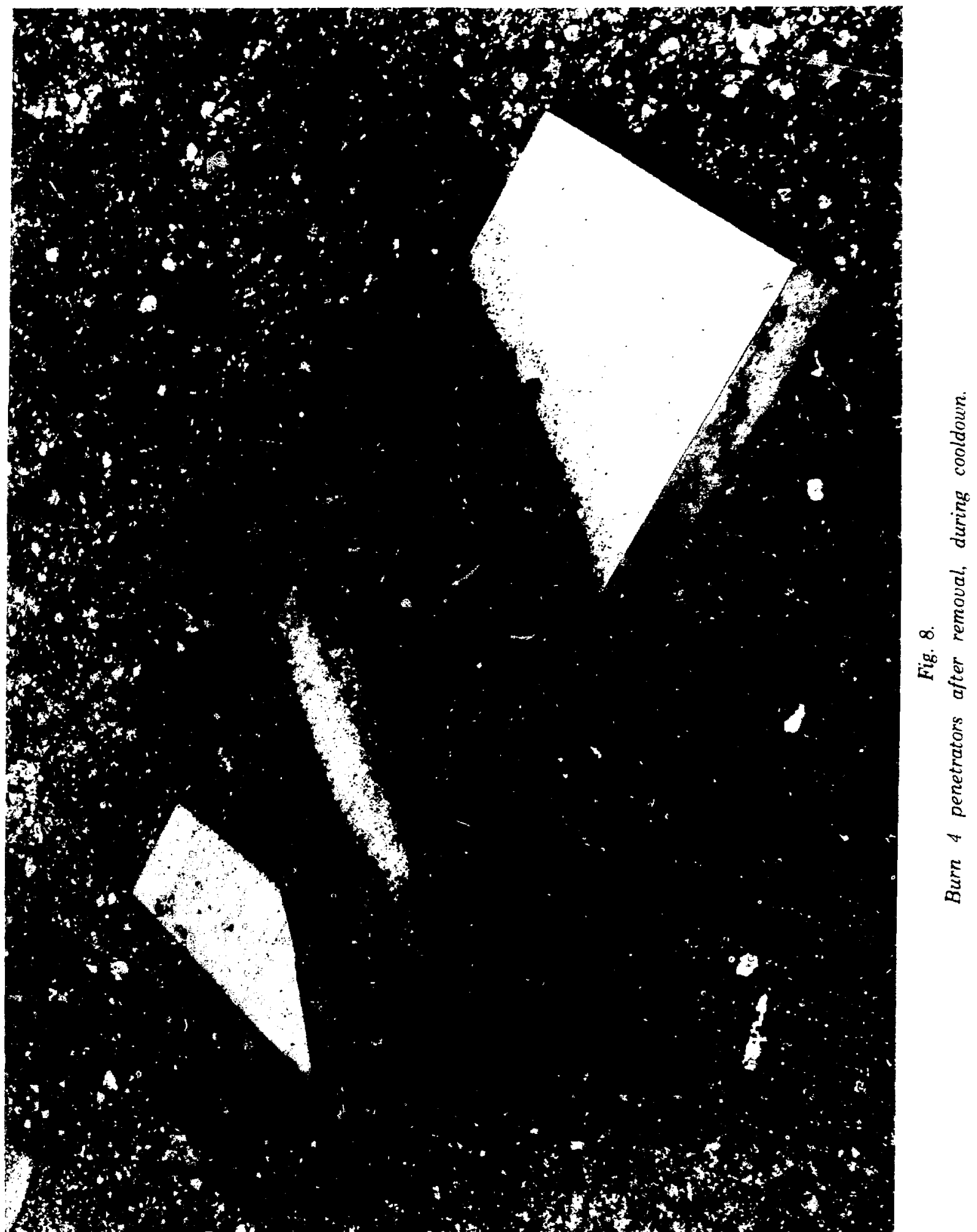

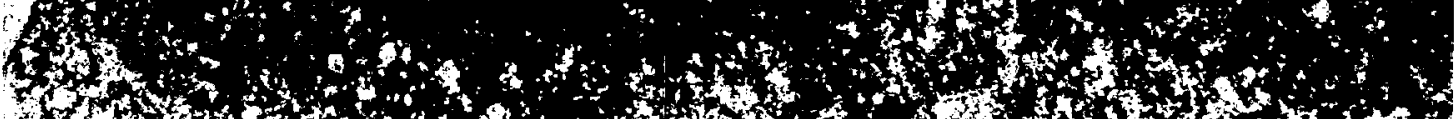

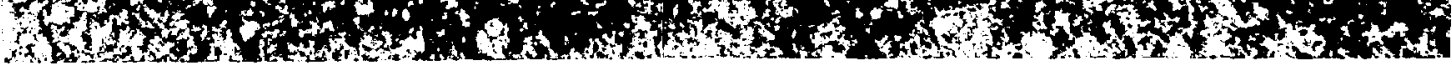




$$
\equiv
$$


JABLE 111

BURA 4 GIR SAMPLING MASSES

\begin{tabular}{|c|c|c|c|c|}
\hline Sample & Saicn ! & Eaten 4 & Batch 8 & Eatch 10 \\
\hline Gross $(47 \mathrm{~mm})$ (ug) & 931 & 15062 & 109407 & 45749 \\
\hline \multicolumn{5}{|l|}{ Ancersen Impactor } \\
\hline 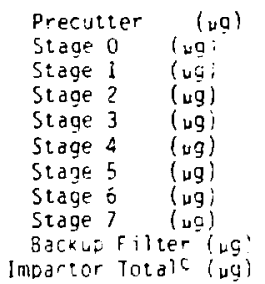 & $\begin{array}{c}482 \\
a \\
a \\
a \\
a \\
a \\
a \\
a \\
e \\
485 \\
97 i\end{array}$ & $\begin{array}{r}5695 \\
1045 \\
58 t \\
345 \\
9.8^{5} \\
13.50 \\
4.5^{5} \\
5.95 \\
5.45 \\
270^{5} \\
7138\end{array}$ & $\begin{array}{c}1399= \\
a \\
a \\
a \\
a \\
a \\
a \\
a \\
a \\
21906 \\
35993\end{array}$ & $\begin{array}{c}14980 \\
a \\
a \\
a \\
a \\
a \\
a \\
a \\
a \\
2440 \\
3938 c\end{array}$ \\
\hline 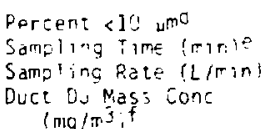 & $\begin{array}{r}50 \\
8 \\
28\end{array}$ & $\begin{array}{r}20 \\
5 \\
28 \\
105\end{array}$ & $\begin{array}{r}u i \\
5 \\
5=\end{array}$ & $\begin{array}{r}E \\
\vdots \\
2 t\end{array}$ \\
\hline
\end{tabular}

JSample not taken (short impactor used.

bparticle size characteristics could not de aralyzed fror. these data due to prenonderance of mass or stage 0 .

c Includes mass collected by precutter.

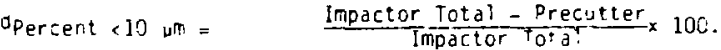

esame sample rate for impactor arid gross sampler.

${ }^{f}$ Calculated fror gross 47-mm sampler mass. Mass concentration based or. the sum of nine masses on impactor stages is not considerec as reliable as a sinale máss or. the gross filter.

IAELE IV

PENE TKATOK OXIUATION

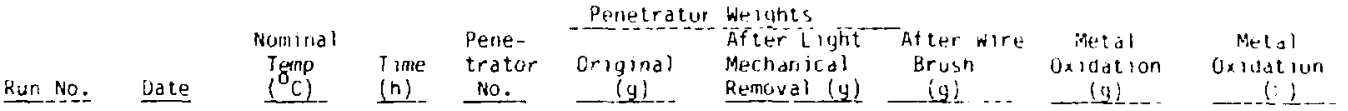

Air dt $223 \mathrm{~cm} / \mathrm{s}$

$\begin{array}{lll}A-774-7 & 05-22-79 & 50 \\ A-774-2 & 05-04-79 & 600 \\ A-774-4 & 05-11-79 & 700 \\ A-774-6 & 05-17-79 & 800\end{array}$

$50 \iota^{\prime}$
600
700
800
900

61512

59603

61310

61501

3354.0

3358.8

3354.9

3354.5

3130.8

3162.0

2640.0

2794.5

3123.8

3149.2

2613.1

2761.5

230.2

209.6

741.8

593.0

$2827.1 \quad 526.9$

6.8

A-774-5 $05-15-79$

3354.0

$2869.4 \quad 2827.1$

$526.0-17.0$

$\mathrm{CO}_{2}$-Air Mixture at $223 \mathrm{~cm} / \mathrm{s}$

M-774-1 05-24-79

$M-774-2 \quad 05-29-79$

$M-774-3 \quad 05-31-79$

$M-774-5$ 06-07-79

$M-774-8 \quad 07-27-79$

$M-774-6$ 06-12-79

\section{0}

600

700

800

$M-774-7$ 06-19-79 1000

$\begin{array}{ll}2 & 61402 \\ 2 & 61406 \\ 4 & 45401 \\ 4 & 45510 \\ 4 & 45104 \\ 4 & 59613 \\ 4 & 45204\end{array}$

3355.0
3353.0
3357.0
3354.2
3355.4
3352.8
3355.0

3156.8
3149.0
2652.9
2405.9
2378.1
2544.2
2586.2

$3153 . ?$

3140.9

201.9

212.1

2642.2714 .8

$2351.1 \quad 1003.1$

$2343.7 \quad 1011.7$

$2518.8 \quad 834.0$

$2564.7 \quad 790.3$

$6 . ?$

2..

15.7

Air at Zero Velocity

N-774-1 05-14-79 


\section{B. Laboratory Oxidation and Aerosol Experiments}

This series of experiments examined the effect of high temperature exposure of bare penetrators under various conditions of air-only and $50 \%$ air $-50 \% \mathrm{CO}_{2}$ at mosphere at $223 \mathrm{~cm} / \mathrm{s}$ velocity and zero velocity over time intervals of 2 or $4 \mathrm{~h}$. General results of these experiments indicated (1) absence of self-sustained oxidation of the penetrators after external heat was removed: (2) major effect of temperature fluctuation on the production of aerosol; and (3) production of aerosol in the respirable size range.

At the end of runs with as-planned temperature histories, substantial amounts of fine black oxide $\left(\mathrm{U}_{3} \mathrm{O}_{8}\right)$ were noted on the bottom of the furnace tube and all penetrators were coated with an apparently intact layer of black oxide. Only during the cool down period under inert at mosphere $\because d$ large portions of the oxide layer spall off due to thermal stress. Since this occurred after samlers were stopped, it is unknown if large amounts of this layered oxide was dispersed as an aerosol during the cool down period.

1. Penetrator Oxidation by Mass Loss. Penetrator to oxidation in the 13 experimental runs of the laboratory series are summarized in 'Table IV. Three other runs, excluded from Table IV due to abnormal temperature fluctuations during the runs, are disc'sed separately in a later section. Figure 10 shows amount of 1$) U$ metal oxide after the high temperature exposures. Light mechanical work and wire brushing was used to remove the oxide. Maximum oxidation in air oc. curred at $700^{\circ} \mathrm{C}(22.1 \%$ in $2 \mathrm{~h})$ and in the air $-\mathrm{CO}_{2}$ mixture at $800^{\circ} \mathrm{C}(30.2 \%$ in $4 \mathrm{~h})$. At 500 and 60()$^{\circ} \mathrm{C}$, oxidation was approximately equal for the 2-h runs for both air and air- $\mathrm{CO}_{2}$. At 800 and $900^{\circ} \mathrm{C}$, the effect of extending the exposure time from 2 to $4 \mathrm{~h}$ was apparent; doubling the exposure time caused oxidation to increase by a factor of 1.6 to 1.7. The gas mixture had a minor effect on oxidation rate at 500 and $600^{\circ} \mathrm{C}$. This is not clearcut at $700^{\circ} \mathrm{C}$, where the mass oxidized in air equaled the mass in air- $\mathrm{CO}_{2}$ in only half the exposure time. On the possibility that this disparity was caused by chemical or heat treatment dissimilarity in the penetrator material, the manufacturer was provided serial numbers for review of chemical analysis. No significant difference was upparent in either the chemical analysis or the heat treatment of the two batches.

$\mathrm{Megaw}^{3}$ noted a sharp increase in oxidation rate between 750 and $850^{\circ} \mathrm{C}$ in both air and pure $\mathrm{CO}_{2}$. The general shape of the temperature vs oxidized metal relationship corresponds to Megaw's results. These results could have been compared more closely if test.s at narrower temperature intervals had provided more detail in the vicinity of the phase transition temperature. A decrease in

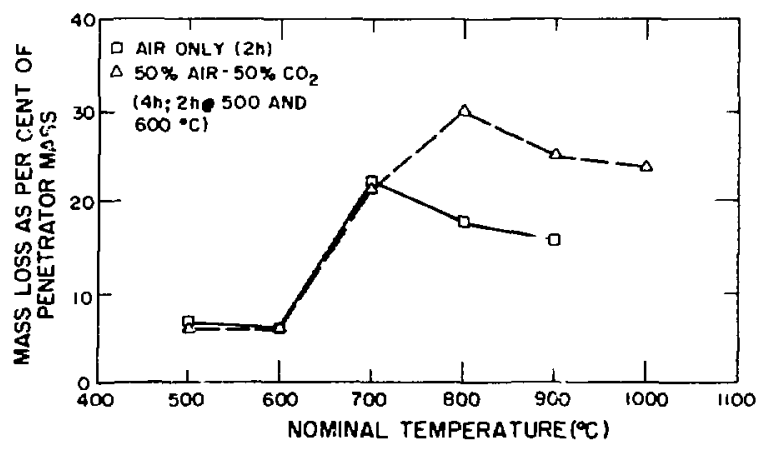

Fig. 10.

Oxitation as a function of temperature. 
oxidation at higher temperat ures indicated (1) a degree of self-protection occurred as a harder oxide laver formed or (2) the gamma phase was not as susceptible to oxidation as the alpha phase. as suggested hy Megaw. ${ }^{3}$

2. Penetrator and Oxide Description. Photographs of penet rators and uxide samples after exposure and cleaning were delivered to ARRADCOM as part of the experimental drcumentation. The photugraphs included with the following descriptiuns were selected as typical or most descriptive of significant results. I'nless noted otherwise, the physical appearance of a penet rator exporsed to air- $\mathrm{CO}_{2}$ mixture was the same as the penetrator exposed to air at the same temperature.

Exposure at $500^{\circ} \mathrm{C}(2 \mathrm{~h})$. The sharp edges of the buttress gronves and threads were (xidized and surfaces roughened by a 2 -h exposure at $500^{\circ} \mathrm{C}$. The oxide came off in long fragile, black layered tragments. some as long as $10 \mathrm{~cm}$ (Fig. 11). Round disks of oxide with holes in the center came from the blunt end of the penetrator. which had a $0.32-\mathrm{cm}$ hole in it.

Exposure at $600^{\circ} \mathrm{C}(2 \mathrm{~h})$. Buttress grooves were oxidized but were still visible after 2 -h $\mathrm{ex}$. posure at $6000^{\circ} \mathrm{C}$. The oxide came off' in long black lavered fragments, which were more resistant to breakage than the $50(1)^{\circ} \mathrm{C}$ oxide as shown in Fig. 12.

Exposure at $700^{\circ} \mathrm{C}(2 \mathrm{~h})$. The penetrator exposed to air at $700^{\circ} \mathrm{C}$ for $2 \mathrm{~h}$ is shown in Fig. 1.3a. The buttress grooves were completely oxidized and deep imprints appeared where the lavice supports conducted heat from the furnace to the penetrator. The effect of tenperature gradient along the penetrator was also apparent with only minimal metal oxidation nccurring at the blunt end. The black oxide contained fewer large fragments and was broken easily into small pieces as shown in Fig. 14.

The effect of air velocity on the oxidation of DL' was investigated in one air run at 70$)^{\circ} \mathrm{C}$ with no flow. The penet rator experienced much lower oxidation (447 g vs $742 \mathrm{~g})$ under no-flow conditions. Difference in the oxictes of the two cases could not be visually detected.

Exposure at $800^{\circ} \mathrm{C}(2$ and $4 \mathrm{~h})$. Sagging of the penetrator was apparent at $800^{\circ} \mathrm{C}$, particularly. after 4 -h exposure (Figs. 13b and 15a). Large pits appeared in the surface over the full length. which was distinctive of this temperature. The black oxides were similar in the 2-h air run (Fig. 16 ) and the 4-h air- $\mathrm{CO}_{2}$ run (Fig. 17), being composed of smaller particles and a few intermediatesize fragments.

Exposure at $900^{\circ} \mathrm{C}\left(2\right.$ and $4 \mathrm{~h}$ ). The penetrators exposed to $900^{\circ} \mathrm{C}$ appeared in better condition than the penetrator exposed at 700 and $800^{\circ} \mathrm{C}$ (Figs. $13 \mathrm{c}$ and $15 \mathrm{~b}$ ). Remnants of buttress grooves were apparent after 2 -h exposure in air. Large pits appeared in the cooler portion of the penetrator exposed for $4 \mathrm{~h}$. The trailing end showed hard, shiny surfaces after wire brushing. The black oxide from the $4 \mathrm{~h}$ air- $\mathrm{CO}_{2}$ run was composed of larger, generally hard, shiny, and dense fragments (Fig. 18). compared to somewhat finer particles from the 2-h run shown in Fig. 19.

Exposure at $1000^{\circ} \mathrm{C}(4 \mathrm{~h})$. The penetrator exposed to $1000^{\circ} \mathrm{C}$ for $4 \mathrm{~h} \mathrm{(Fig.} \mathrm{15c)} \mathrm{was} \mathrm{quite}$ similar to the $900^{\circ} \mathrm{C}$ penetrator, except for slightly more evidence of buttress grooves. The bulk of its black oxide was also compcsed of large, hard, dense fragments (Fig. 20).

3. Aerosol Sizing Results. Aerosol size expressed as mass median aerodynamic diameter ( $\mathrm{mmad}$ ) of particles passing the precutter is displayed as a function of temperature in Fig. 21. Geometric standard deviation $\left(\sigma_{\mathrm{g}}\right)$ of these aerosols ranged from 1.7 to 3.6 and indicated a 

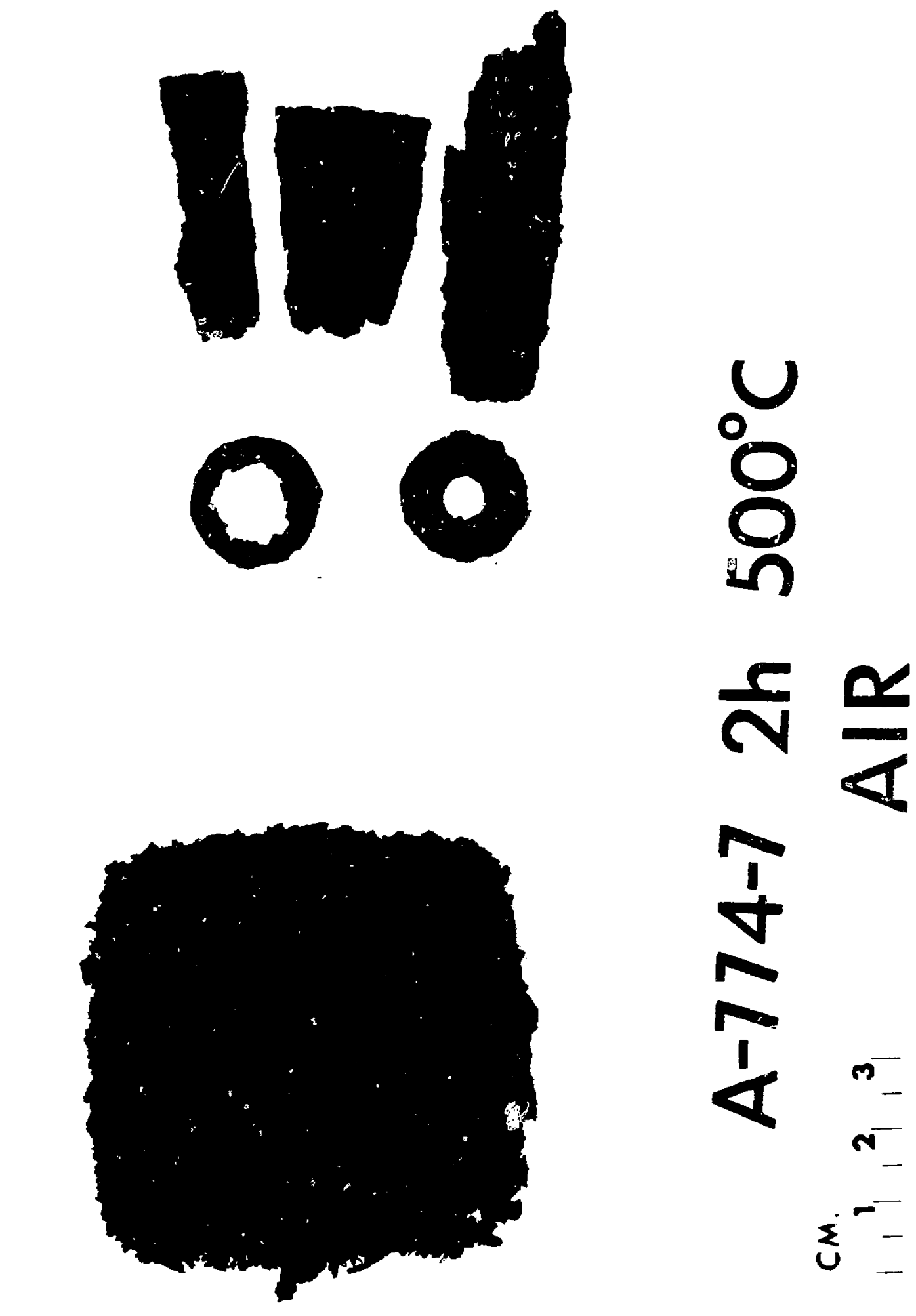


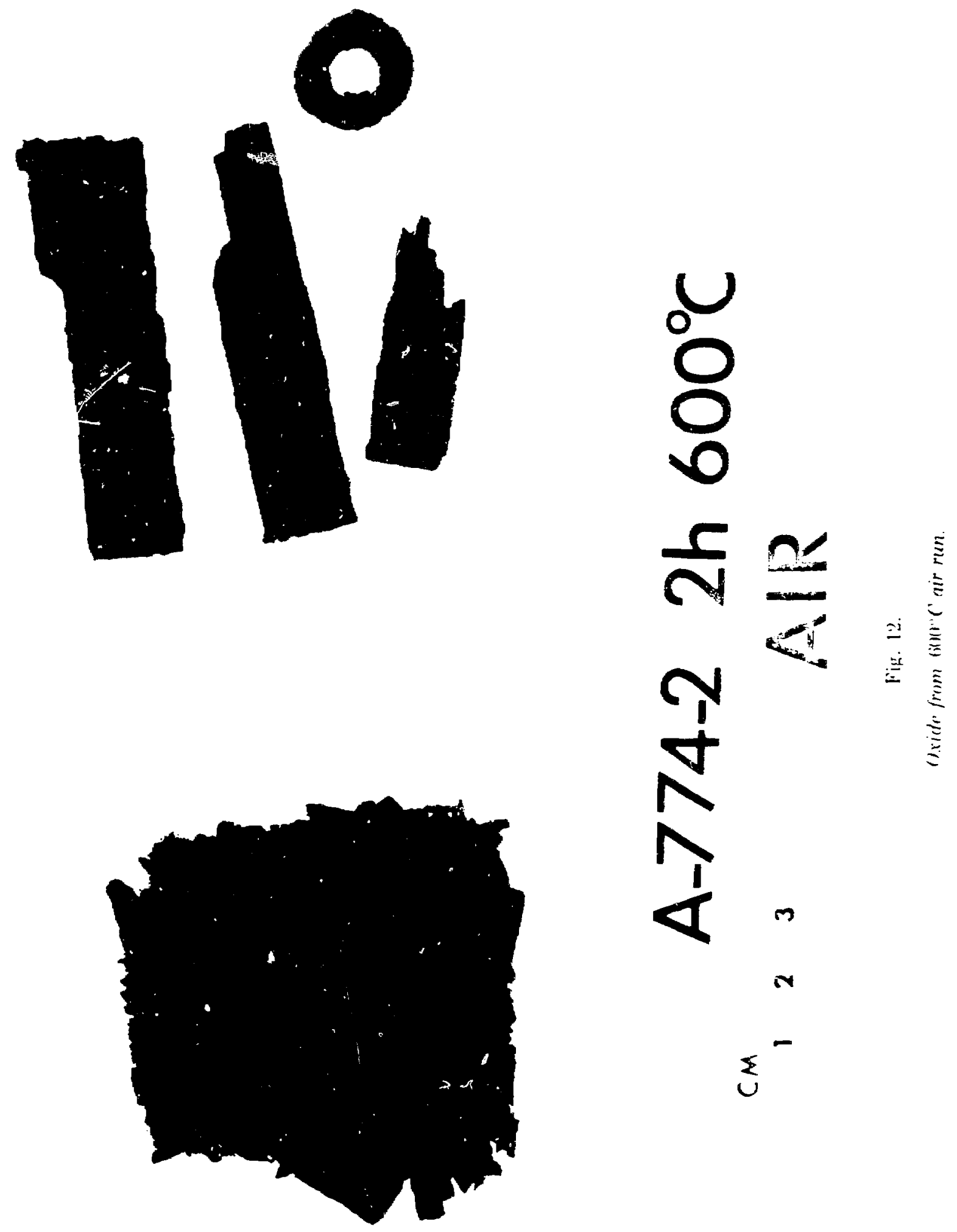



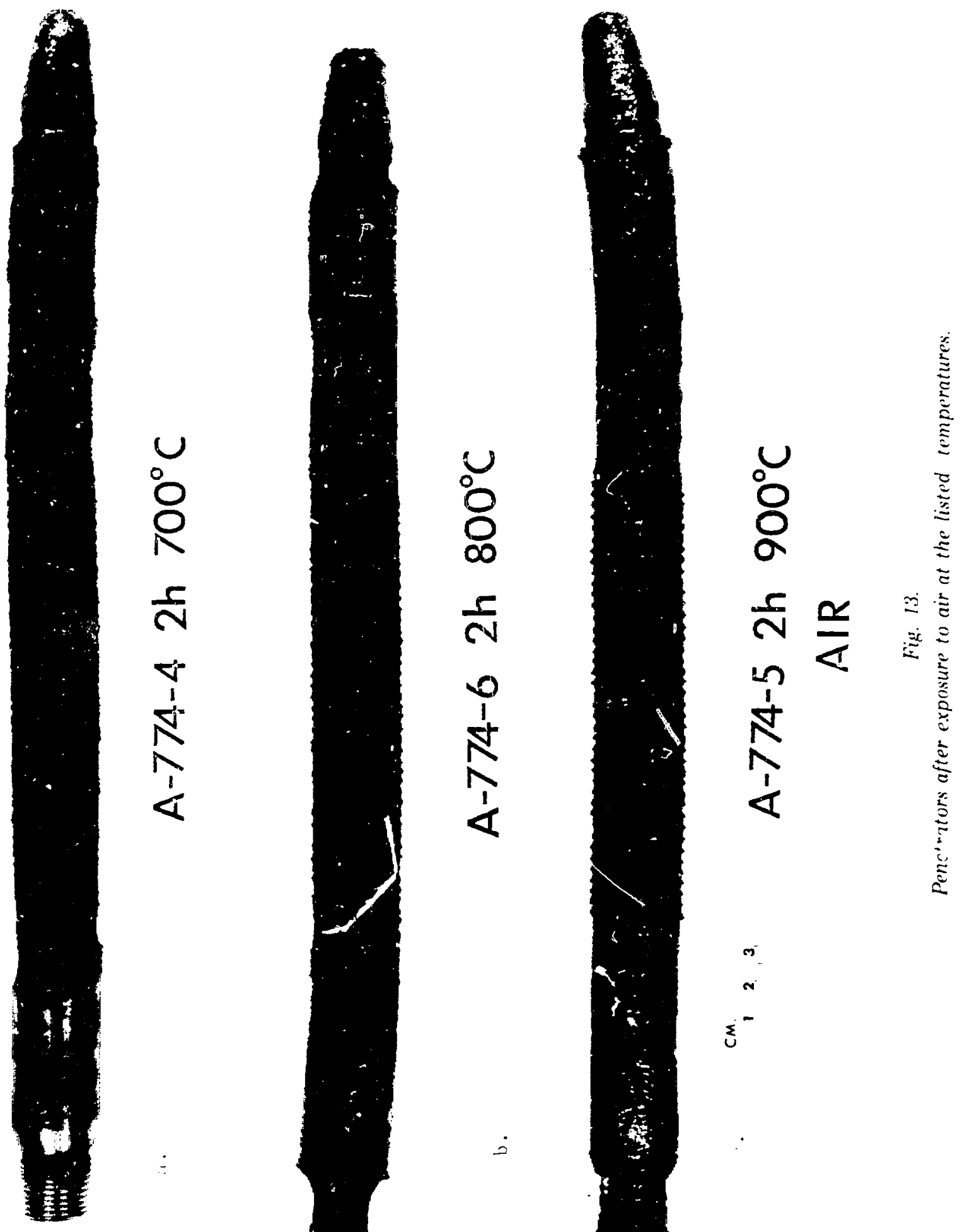

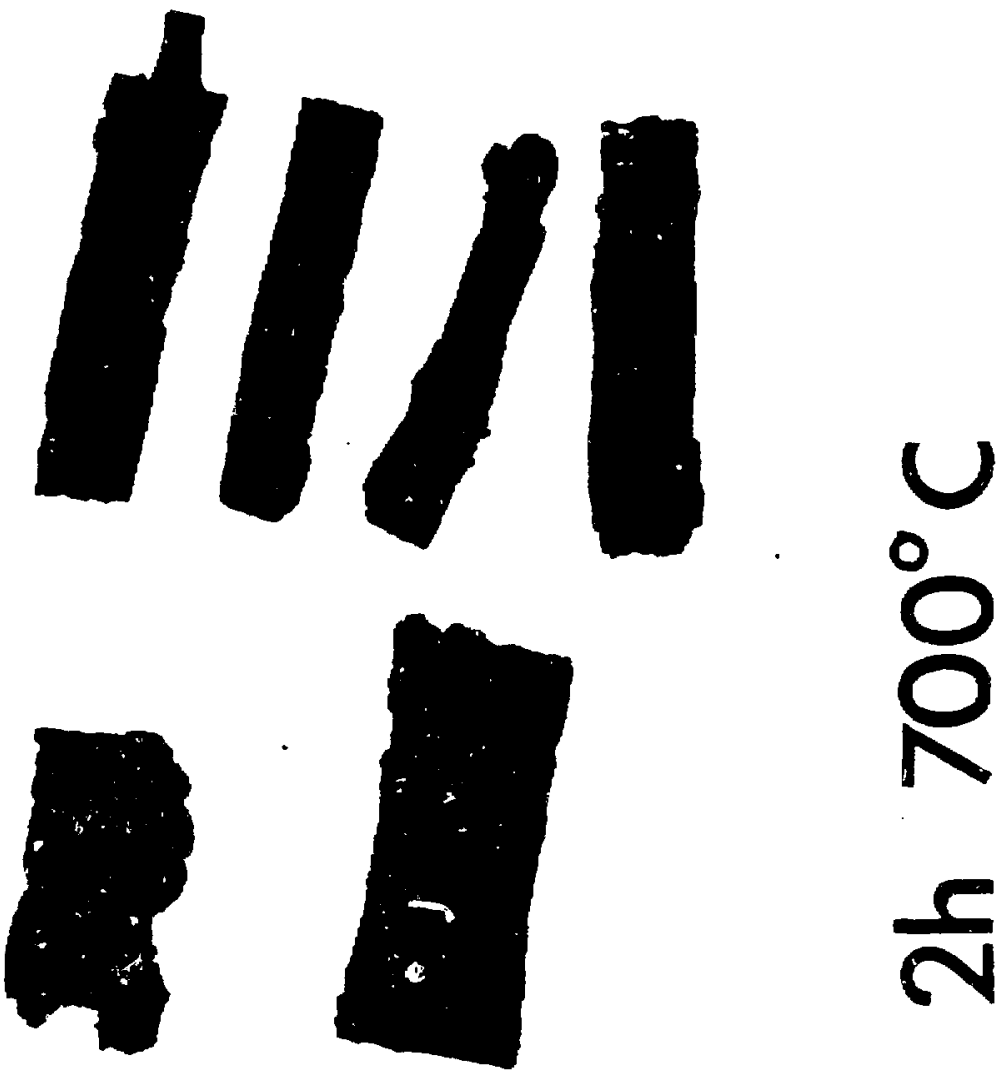

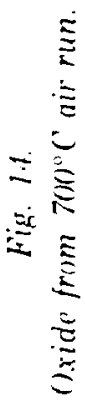

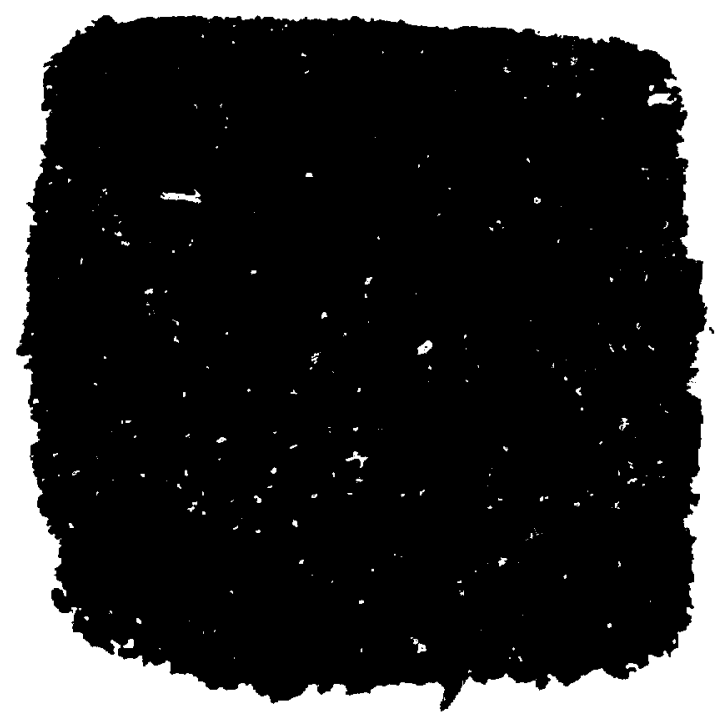

6

(2)
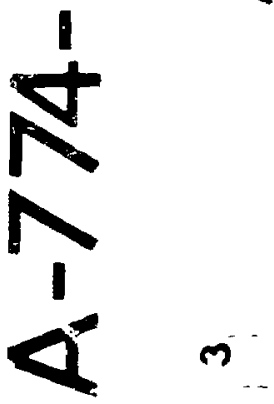

N

$\sum^{-}$ 


$$
\equiv
$$



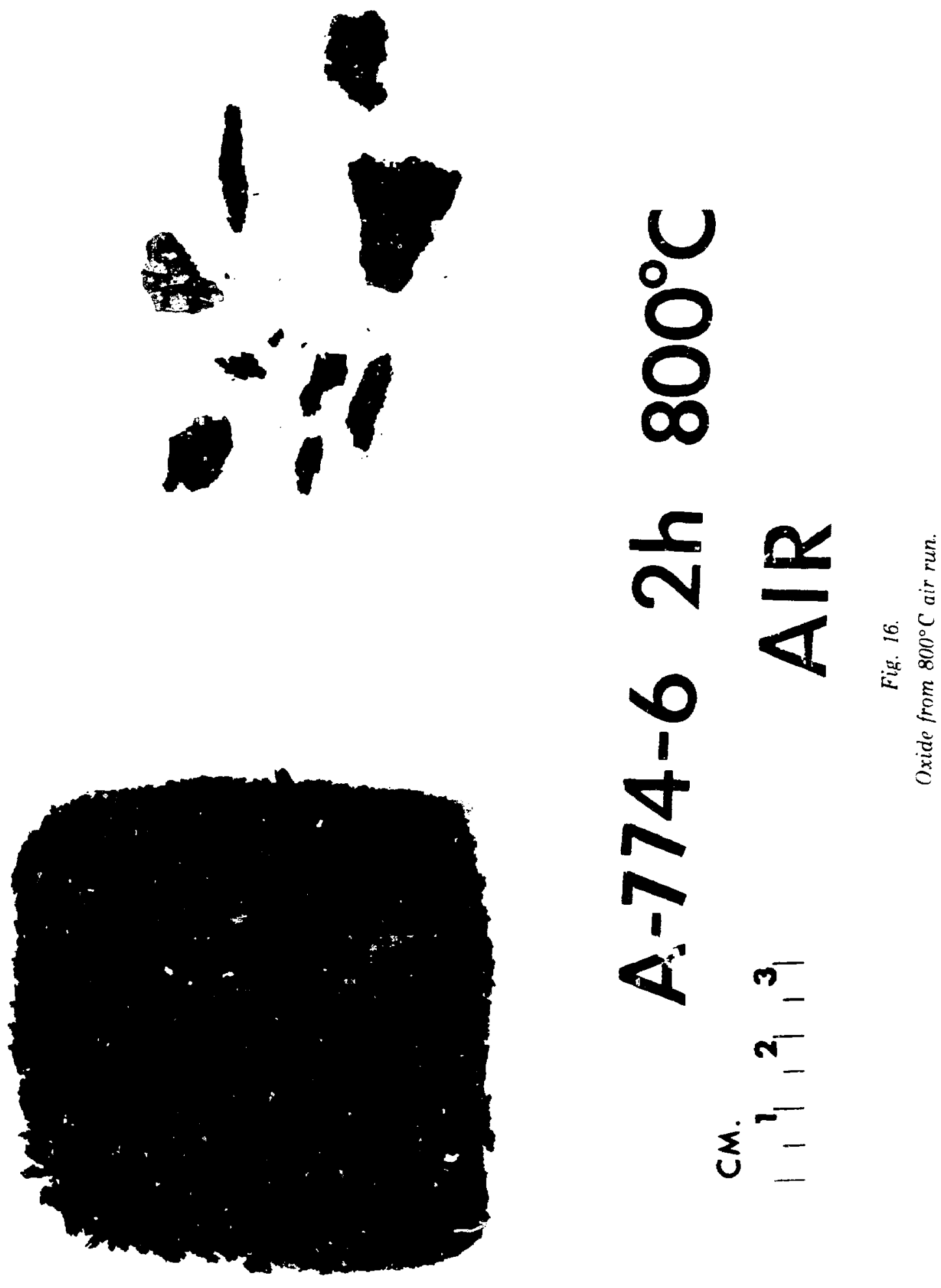

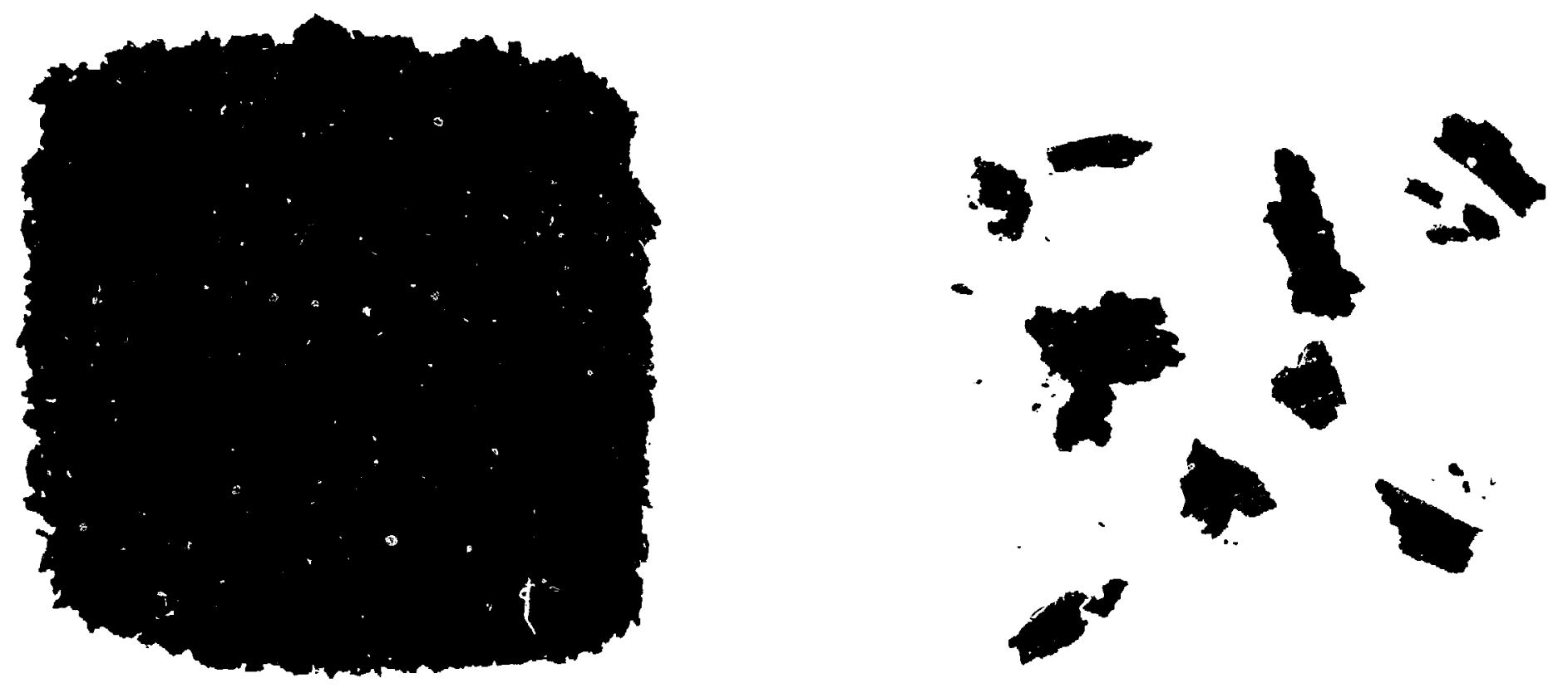

$$
M-774-5 \quad 4 h \quad 800^{\circ} \mathrm{C}
$$

CM.

$$
\mathbf{1}_{1}, \mathbf{3}
$$$$
\mathrm{CO}_{2}-\mathrm{AIR}
$$ 

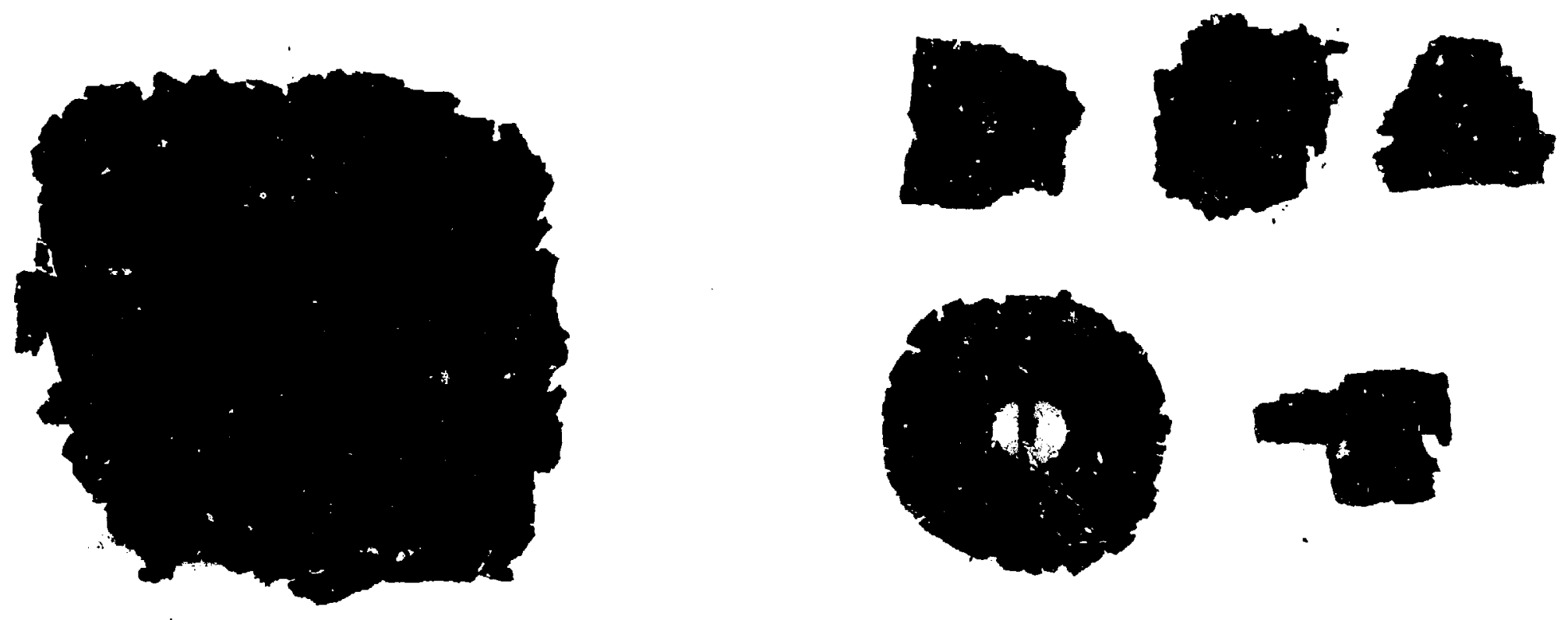

\section{M-774-6 4h $900^{\circ} \mathrm{C}$}

CM.

$\left|\begin{array}{llll}1 & 1 & 1 & 2\end{array}\right|$
$\mathrm{CO}_{2}-\mathrm{AIR}$

Fig. 18.

Oxide from $900^{\circ} \mathrm{C} \mathrm{CO}_{2}$-air run. 

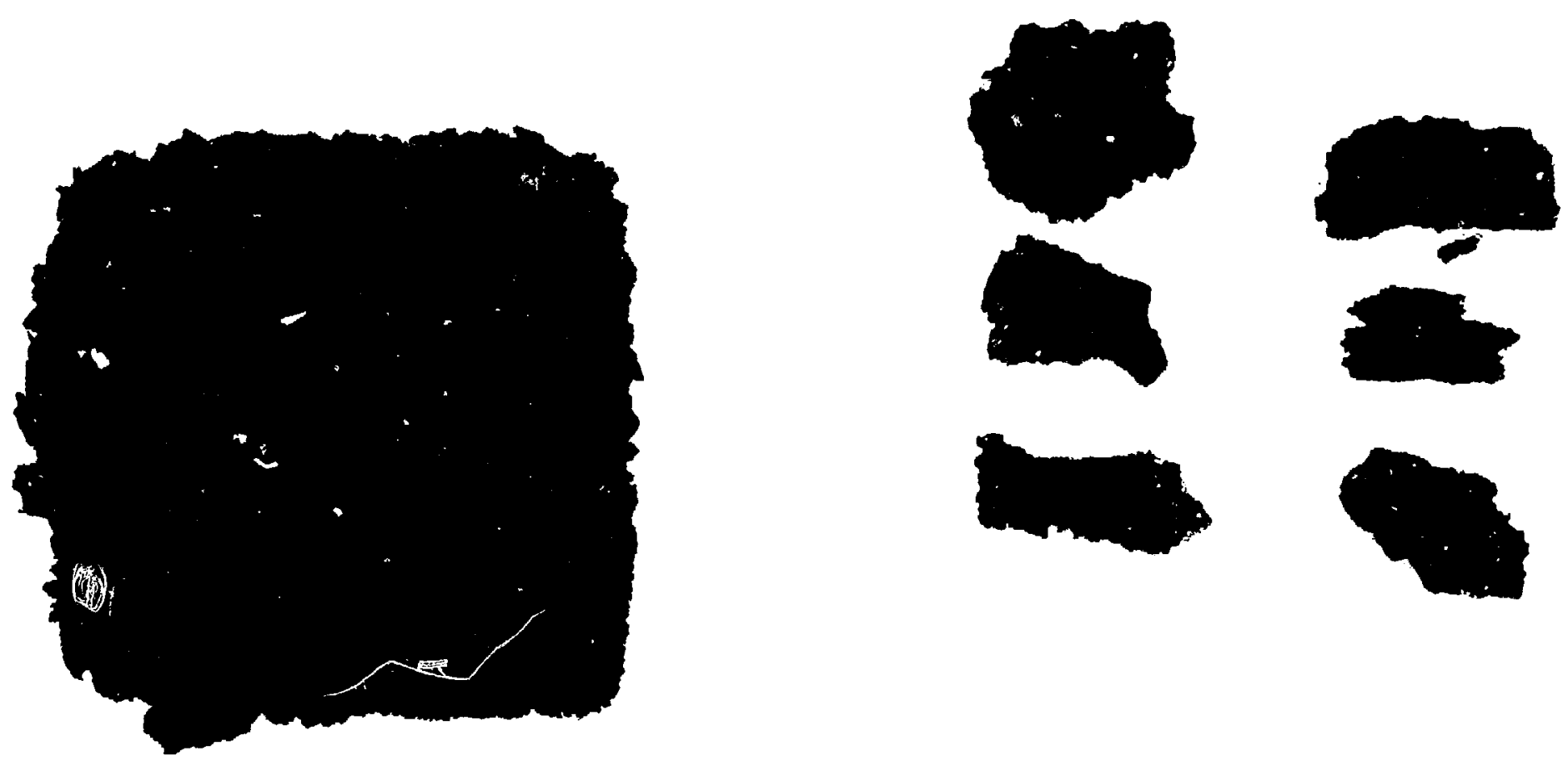

A-774-5 $2 \mathrm{~h} 900^{\circ} \mathrm{C}$

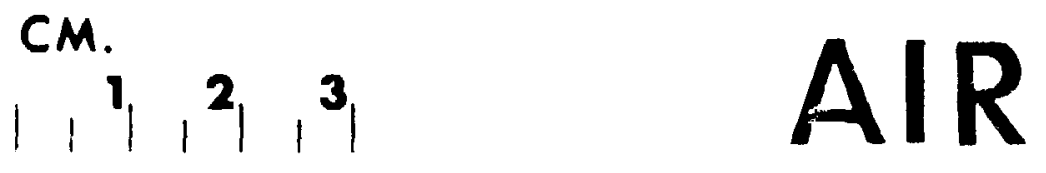



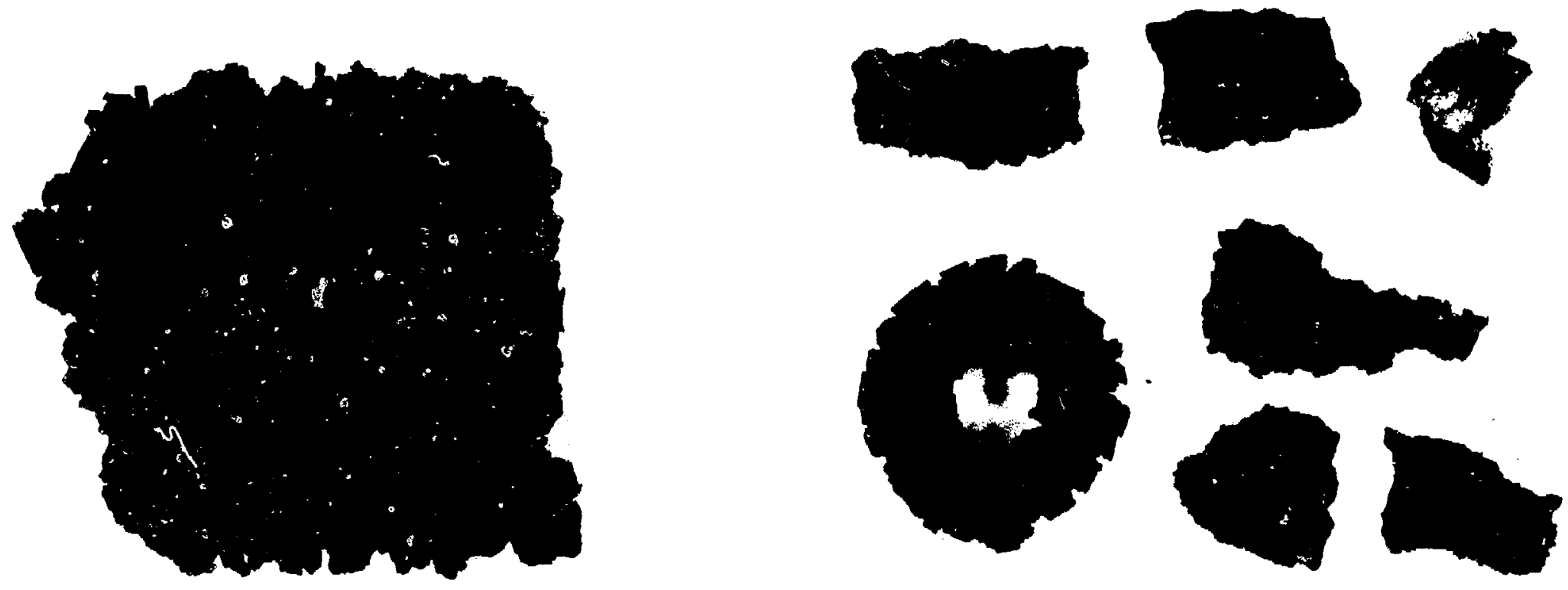

CM.

M-774-7 $4 \mathrm{~h} 1000^{\circ} \mathrm{C}$

$|1|, 2,1\}$

$\mathrm{CO}_{2}-\mathrm{AIR}$ 


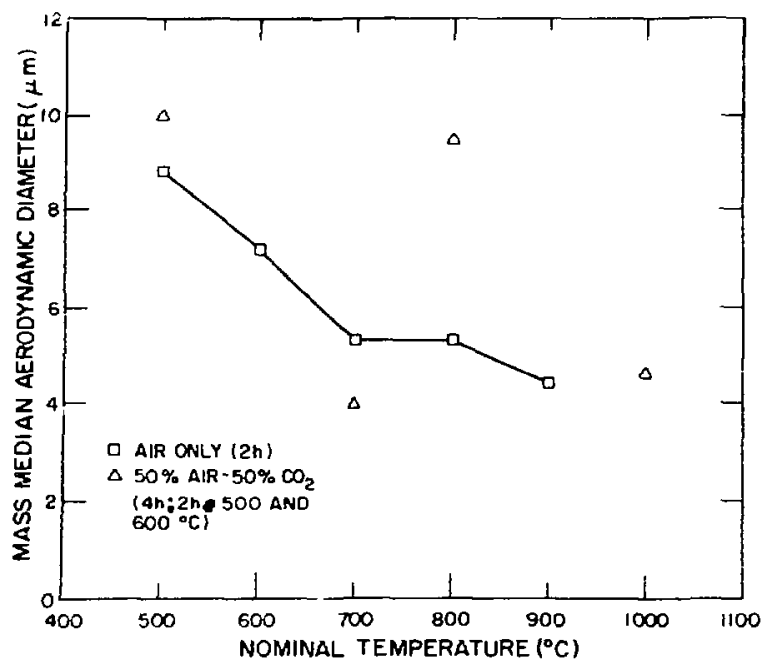

Fig. 21.

Size of aerosol $<10-\mu m$ as a function of temperaturt.

somewhat broader size distribution at the 500 to $700^{\circ} \mathrm{C}$ temperatures than at the 800 to $1000^{\circ} \mathrm{C}$ temperatures. The mmads for the air runs dropped uniformly from $9 \mu \mathrm{m}$ to $4.5 \mu \mathrm{m}$ as temperature was increased from 500 to $900^{\circ} \mathrm{C}$. The air- $\mathrm{CO}_{2}$ results were not consistent with the air-only results at all temperatures, although the mmads remained generally in the same range $(4-10 \mu \mathrm{m})$. Fewer data made it more difficult to establish a trend for the air- $\mathrm{CO}_{2}$ results (the $600^{\circ} \mathrm{C}$ point was omit ted because of insufficient mass collected; the $900^{\circ} \mathrm{C}$ point, because low mass collection in the precutter made the result suspect). Of the four data remaining, only the $800^{\circ} \mathrm{C}$ result $(9.5 \mu \mathrm{m})$ differs significantly from the air-only result $(5.3 \mu \mathrm{m})$. A possible source of variation $n$ the air- $\mathrm{CO}_{2}$ runs not present in the air runs was a $\mathrm{CO}_{2}$ bottle change operation, which induced a $75-100^{\circ} \mathrm{C}$ temperature rise lasting about $1 \mathrm{~min}$. This temperature change may have caused unusual aerosol production because of therm al expansion and contraction at the penetrator surface. Each run had at least one $\mathrm{CO}_{2}$ bottle change; the $900^{\circ} \mathrm{C}$ and $1000^{\circ} \mathrm{C}$ runs each had two changes.

Total aerosol mass collected on all impactor stages, the precutter, and in the high volume sampler is expressed as percent of penetrator mass in Fig. 22. The total mass of aerosol collected ranged between $10^{-4}$ and $10^{-2} \%$ of penetrator mass, the maximum occurring in the $1000^{\circ} \mathrm{C}$ air- $\mathrm{CO}_{2}$ run. The scatter present in the data and different test durations do not permit a clearcut identification of whether there is an effect on aerosol production when $\mathrm{CO}_{2}$ is added to the atmosphere. The trend of aerosol mass vs temperature was generally the same for the two gas atmospheres if the time differential between 2 and $4 \mathrm{~h}$ is taken into account. Aerosol mass was lowest at $500-600^{\circ} \mathrm{C}$, increased sharply at $700^{\circ} \mathrm{C}$, decreased somewhat at $800^{\circ} \mathrm{C}$, and increased again in the $900-1000^{\circ} \mathrm{C}$ range. The $900^{\circ} \mathrm{C}$ point from the air $-\mathrm{CO}_{2}$ runs was not omitted from Fig. 22 as it was from Fig. 21 since the impactor mass had a negligible effect on the results $d r$ iribed in Fig. 22 .

An estimate of aerosol mass associated with particles smaller than $10 \mu \mathrm{m}$ as a percent of penetrator mass was obtained by multiplying the fraction of collected aerosol passing the precutter by the total aerosol mass as a percent of penetrator mass (Fig. 23). This result is considered a conservatively high estimate since mass concentration calculated from high volume sampler mass and sample volume exceeded by factors of 3 to 4 the mass concentration calculated similarly from 


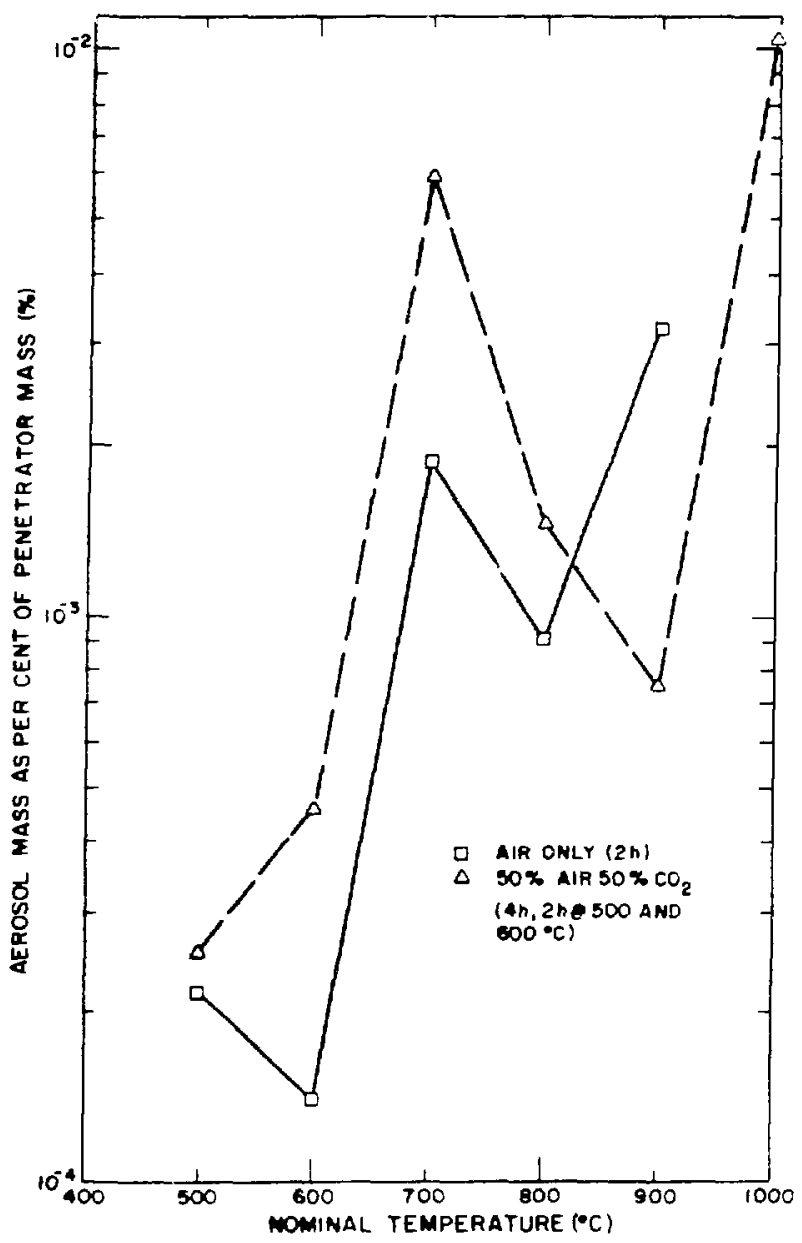

Fig. 22.

Aerosol mass as a function of temperature.

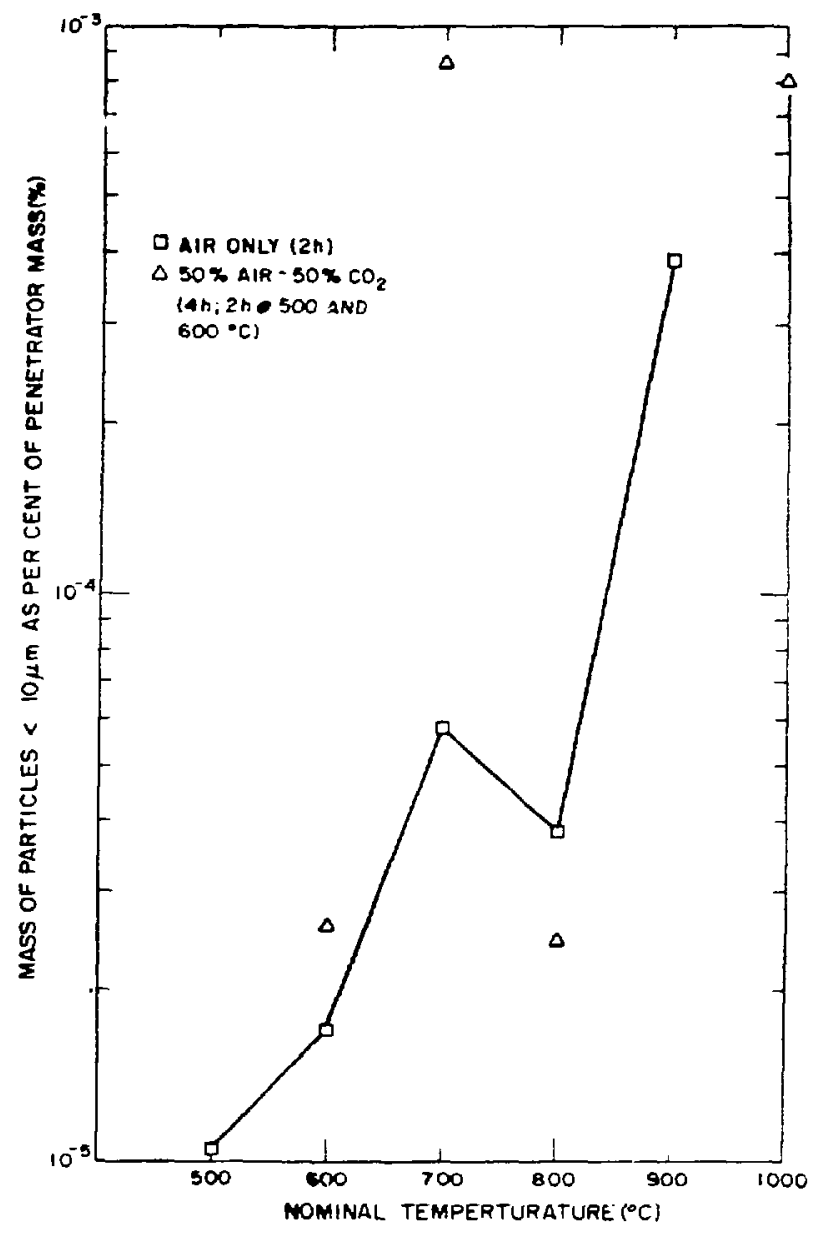

Fig. 23.

Respirable mass as a function of temperature.

impactor data. The probable cause of this discrepancy was placement $0_{i}$ the impactor probe at the centerline of the exit tube. Sedimentation of larger particles could be expected to cause higher concentration of larger particles below the centerline of the tube, which the high volume sampler would collect but the impactor would not. The impactor, therefore, provided mass concentration of particles more likely to remain airborne a longer length of time. These estimates in Fig. 23 show a general increase in total mass associated with particles smaller than $10 \mu \mathrm{m}$ as temperature increases. Again several discrepancies appeared in the data for the reasons described earlier. The very high value for the $700^{\circ} \mathrm{C}$ air $-\mathrm{CO}_{2}$ run may be real, in that no experimental problem was identified nor was the mass analysis dubious because of insufficient sample size.

4. Effects of Temperature Change During the Run. Runs at 500 and $700^{\circ} \mathrm{C}$ in air and $800^{\circ} \mathrm{C}$ in air- $\mathrm{CO}_{2}$ were omitted from earlier discussions because each had a temperature irregularity during the run, which prompted repeating the run. Each run showed higher oxidation and aerosol mass than the repeated run at the same nominal temperature. Rapid cooling at some point in the 
run apparently caused oxide coating to spall off, exposing new surface to oxidation and aerosolizing more material. The $8000^{\circ} \mathrm{C}$ run showed remarkably high aerosol mass for its short duration (ij) min at $800^{\circ} \mathrm{C}$ plus $18 \mathrm{~min}$ cooling to $\left.625^{\circ} \mathrm{C}\right)$.

5. Aerosol Production as a Function of Time. Aerosol production as a function of time was first observed on a qualitative basis using the GCA respirable mass monitor. Positive detection of an aerosol occurred within the first 6 min on all runs with nominal temperat ure of 70$)^{\circ} \mathrm{C}, \mathrm{r}$ above. At lower temperatures, mass concentration was apparently lower than the minimum detection limit of the instrument. 'The high temperature runs, notably 900 and $1000^{\circ} \mathrm{C}$, exhibited positive readings over the first 1 to $2 \mathrm{~min}$ after gas flow was initiated, then diminished after $10-15 \mathrm{~min}$. This early production of aerosol prompted another oxidaiion run at $8000^{\circ} \mathrm{C}$ for $4 \mathrm{~h}$ in which high volume samples and aerosol weight percent $<10 \mu \mathrm{m}$ vere determined over eight 30 -min intervals.

Fiffects on the penetrator during this run were quite similar to the earlier $8000^{\circ} \mathrm{C}$ run with net metal oxidation of $1011.7 \mathrm{~g}$ and $1003.1 \mathrm{~g}$, respective $y$. B 30 th penetrators were distinctively pitted with large pits. A complete log of data from this run $(\mathrm{M}-7 \mathbf{7 4 - 8 )}$ is included in Table IV.

Aerosul masses collected in the impactor and in the high volume sampler in each of the 30 -min intervals are displayed in Fig. 24. "The impactor tata show a major increase in aerusol mass in the second interval and another increase in the fourth interval. The high volume sampler indicated consistent aerosol mass through the first three intervals followed by a major increase in the fourth interval. The increased amount in the fourth interval coincided with the only $\mathrm{CO}_{2}$ bot tle change and may have been caused by this perturbation. Both samplers indicated a gradual reduction in aerosol production after $2-1 / 2 \mathrm{~h}$, but did not compare well in the earlier part of the run. Since a vertical mass concent ration gradient in the exit tube is probable (as described earlier), the sharp rise in mass collected by the impactor in the second interval may indicate a temporarily higher release of smaller particles. Smaller particles, probably in the range of $10-$ to $20-\mu \mathrm{m} \mathrm{D}_{\mathrm{au}}$, could have been collected in higher numbers at the impactor probe inlet without causing a similar large effect in the high volume sampler mass.

The primary results of this experiment are the initiation of aerosol production very early in the exposure period; and the gradual decrease of aerosol production with time after $2-1 / 2 \mathrm{~h}$.

6. Particle Size Analysis by Sieving. The coarse oxide particles left in the flrmace tube or removed from the penetrator by light mechanical work were sieved by standaraized methods down to 400 mesh $(38 \mu \mathrm{m})$. Particle size analysis of sieve weight data was pertormed as shown in Tyler Screen Scale diagrams attached as Addendum B. Cumulative percent of weight retained was plotted in these diagrams against mesh opening. Midpoint $(50 \%)$ values from these plots are presented in Fig. 25 to indicate the variation in central tendency of sieve particle size as a function of exposure temperature. Particle size of the sieved oxide from the air-only runs decreased with increasing temperature from $570 \mu \mathrm{m}$ at $500^{\circ} \mathrm{C}$ to $180 \mu \mathrm{m}$ at $700^{\circ} \mathrm{C}$. The midpoint size increased at 800 and $900^{\circ} \mathrm{C}$. The drop in sieve particle size between the 500 to $600^{\circ} \mathrm{C}$ runs was more pronounced in the air- $\mathrm{CO}_{2}$ runs. Results of the no-flow run at $700^{\circ} \mathrm{C}$ and the air-only run at $700^{\circ} \mathrm{C}$ were in close agreement, indicating a negligible effect of flow on particle size as defined by sieve analysis.

Megaw $^{3}$ observed only an increase in particle size at $600^{\circ} \mathrm{C}$ and above. Coleman ${ }^{2}$ performed similar measurements at 400,500 , and $600^{\circ} \mathrm{C}$ but did not observe a particle size decrease. The $50 \%$ retained sieve size for $600^{\circ} \mathrm{C}$ in air was compared among these experiments: approximately $130 \mu \mathrm{m}$ by Coleman, $10-40 \mu \mathrm{m}$ by Megaw, $8 \mathrm{nd} 420 \mu \mathrm{m}$ in this experiment. At $800^{\circ} \mathrm{C}$, agreement was no better: $500 \mu \mathrm{m}$ by Coleman, $80 \mu \mathrm{m}$ by Megaw, and $240 \mu \mathrm{m}$ in this experiment. This variation may be caused by differences in sieving practice, that is, percent values in this experiment were based on mass passing a No. 12 screen. The other experimenters may have chosen other methods. 


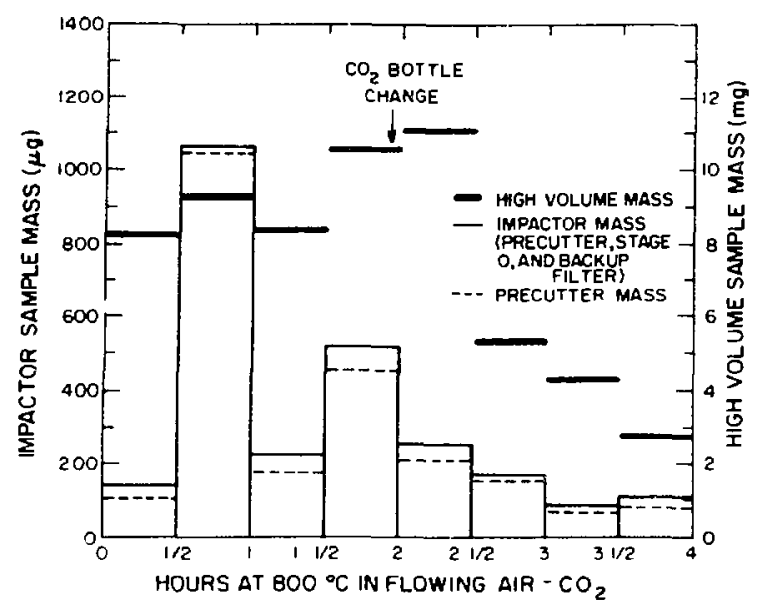

Fig. 24.

Aerosol mass as a function of time.

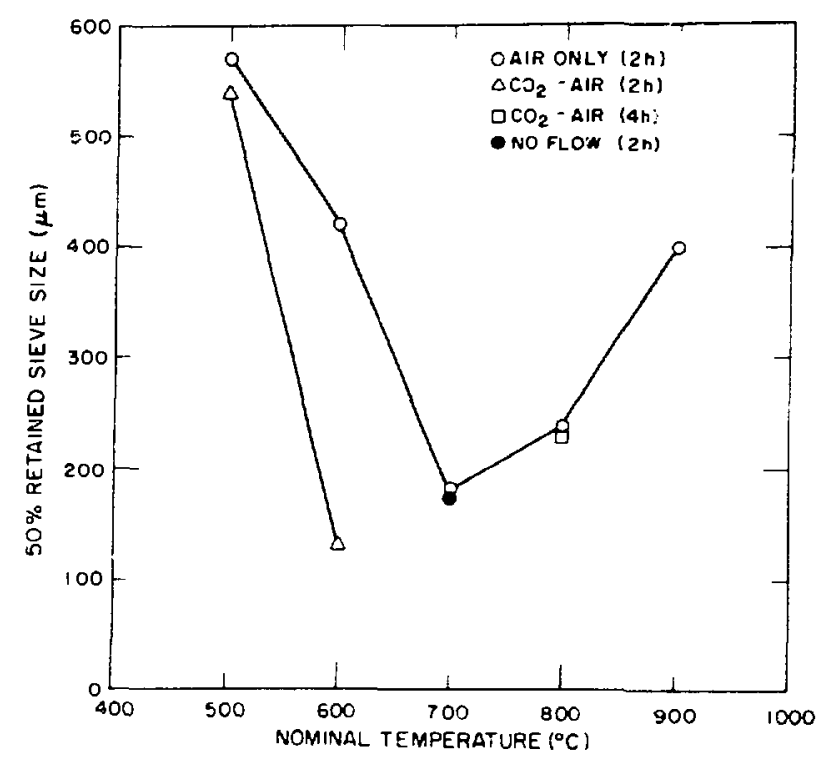

Fig. 25.

Sieve particle size as a function of temperature.

7. Particle Size Analysis by Sedimentation. The average Stokes and aerodynamic equivalent diameters of the oxide $<38 \mu \mathrm{m}$ (passing the No. 400 sieve) are displayed as a function of nominal furnace temperature in Fig. 26. Sedimentution analysis permitted assigning an equivalent diameter to each oxide batch in the absence of a detailed particle shape determination.

The $D_{\mathrm{ge}}$ increased with increasing temperature from approximately $35 \mu \mathrm{m}$ at $500^{\circ} \mathrm{C}$ to $60-6.5 \mu \mathrm{m}$ at $800^{\circ} \mathrm{C}$. The particle size distribution of the oxide was bimodal. The major and minor mode diameters and tive average diameter are included in-Fig. 26. The effect of temperature on $D_{\mathrm{a}}$ determined by sediment at ion analysis of the mass fraction of oxide $<38 \mu \mathrm{m}$ indicated a different trend than was observed earlier with air samples. The Andersen impactor samples indicated that the mean particle size decreased with increasing temperature while the sedimentation analysis indicates that particle size increased with increasing temperature. However. the sedimentation analysis includes particles that are much larger than the maximum size collected by the impactor, therefore representing a different set of particles. Sedimentation analysis includes particles having $D_{\mathrm{ae}}$ over $100 \mu \mathrm{m}$ while the impactor analysis includes particles having diameters up to 10 $\mu \mathrm{m}$. The impactor data is more closely related to the minor mode data in which the particle size shows a slight decrease with increasing temperature.

Although there were only two $2-\mathrm{h}$ air $-\mathrm{CO}_{2}$ runs, the $500^{\circ} \mathrm{C}$ and $600^{\circ} \mathrm{C}$ data differed only 10 to $20 \%$ from the air-only runs, as shown in Fig. 26. The 4-h air- $\mathrm{CO}_{2}$ run at $800^{\circ} \mathrm{C}$ and the no-flow run at $700^{\circ} \mathrm{C}$ were in close agreement with the air-only runs, showing negligible effect of at mosphere or time-at-temperature in the $<400$-nesh size range.

Figure 27 shows weight percent for material with $<10-\mu \mathrm{m}$ aerodynamic equivalent diameter estimated from the sedimentation results. This information is of interest as an estimate of the fraction (by weight) of the $<38-\mu \mathrm{m}$ oxide which is in the respirable $(<10 \mu \mathrm{m})$ range. Also included for comparison is weight fraction of the total oxide which was small enough to pass the 400 -mesh sieve. For the air-only runs, the weight percent of the $<400$-mesh oxide which is in the $<10-\mu \mathrm{m}$ $D_{a e}$ range was $8 \%$ at $500^{\circ} \mathrm{C}(0.04 \%$ of the total penetrator $)$ and $14 \%$ at $900^{\circ} \mathrm{C}(0.07 \%$ of the total 
penetrator). (omparison of these values to aerosol mass as a percent of penetrator mass in Fig. 233 shows at $9000^{\circ} \mathrm{C}$ only $0.0004 \%$ was aerosolized us $0.07 \%$ retained in the oxide; at $5000^{\circ} \mathrm{C}$. $0.00001 \%$ is $0.10 \%$. Thus, only a small fraction of those DL oxide particles of apparently entrainable size actually hecame a' rhorne. Other results shown in Fig. 27 were unremarkable except for the large increase of cxide particles $\angle 40(1)$-mesh produced in the $6000^{\circ} \mathrm{C}$ air $-\mathrm{CO}_{2}(2 \mathrm{~h})$ run. A difference in temperature history during the run is a possible cause; chart records show acceptable cont rol during both runs. except for one extra $\mathrm{CO}_{2}$ bottle change occurring in the $600^{\circ} \mathrm{C}$ run.

8. X-ray Diffraction Analysis of DU Oxide. Dl oxide powder samples from the 2 -h runs were examined by $x$-ray diffraction methods principally for phase identification and to ascertain any variations in crystallinity, which might be attributed to temperat ure history. The principal phase present was ${ }_{3}{ }_{3} \mathrm{O}_{\mathrm{A}}$ (orthorhombic); however, $\mathrm{CO}_{2}$ was present in all samples in amounts langing from a trace $t o$ several percent.

All results are summarized in Table $\mathrm{V}$. The effective crystallite size of the $\mathrm{C}_{3} \mathrm{O}_{8}$ increases with temperature; there appears to be little dependence on the atmospnere or time-at-temperature. The crystallites exhibit much greater perfection in the pole (reference) direction than in any direction perpendicular $0 \mathrm{t}$ his pole, an indication of a columnar, lavered configuration. The $\mathrm{I}^{\circ} \mathrm{O}_{2}$ phase increases in relative amount with temperature. The anomolously high relative amount of $\left.10^{\circ}\right)_{2}$ in the $700^{\circ} \mathrm{C}^{\circ}$-no airflow sample has no readily apparent cause but could be due to less available oxygen in the no airfow experiment.

9. Scanning Electron Microscopy (SEM) of DU Oxide. SFM examination of < 400 - mesh samples was performed for morphological observation only: particle size characterization was not an objective. (Oxide particles were manually dispersed from the bulk powder onto an adhesivecrated aluminum specimen stub. While the adhesive was still wet, a mild airst ream was blown across the sample by syringe to remove loose material.

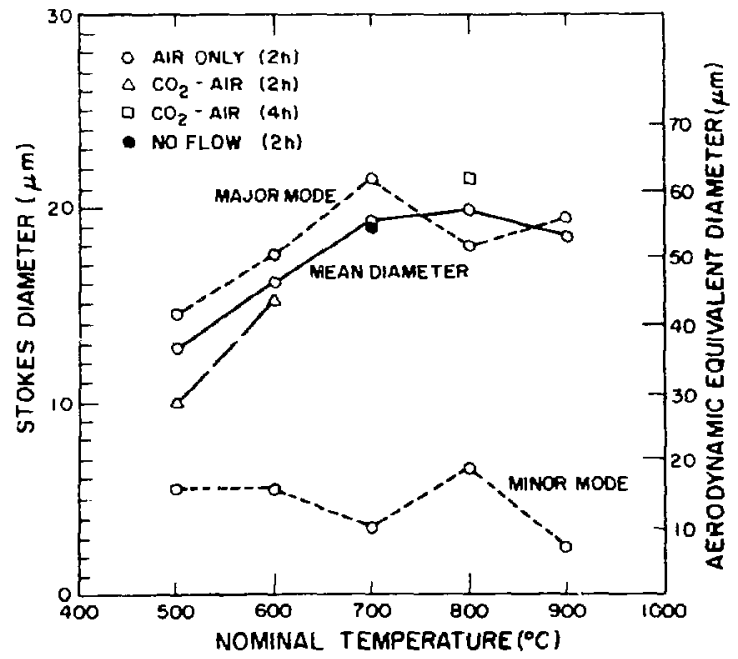

Fig. 26.

Stokes diameter of particles $<38 \mu m$ as a function of temperature.

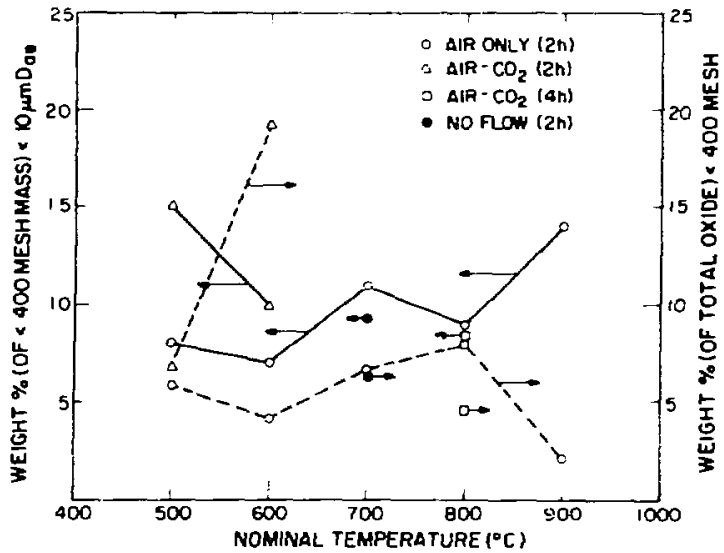

Fig. 27.

Mass distribution in sub-400 mesh sieve fraction. 


\begin{tabular}{|c|c|c|c|c|c|}
\hline \multirow{2}{*}{$\begin{array}{l}\text { Sample } \\
\text { No. }\end{array}$} & \multicolumn{3}{|c|}{ Test Conditions } & \multirow{2}{*}{$\begin{array}{l}\text { Effective } \\
\text { Crystallite } \\
\text { Size (A) }\end{array}$} & \multirow{2}{*}{$\begin{array}{c}\text { Relative } \\
\text { UO } \\
\text { Arrount } \\
\end{array}$} \\
\hline & Temp $\left({ }^{\circ} \mathrm{C}\right)$ & Time & Atmosphere & & \\
\hline$A-774-7$ & 500 & $2 \mathrm{~h}$ & Air & 730 & 0.35 \\
\hline$A-7 / 4-2$ & 600 & $2 n$ & Air & 1100 & 0.73 \\
\hline$A-774-4$ & 700 & $2 \mathrm{n}$ & Air & 1700 & 0.82 \\
\hline$A-7>4-6$ & 800 & $2 n$ & Air & 2300 & 0.99 \\
\hline$A-774-5$ & 900 & $2 n$ & Air & 3800 & 4.24 \\
\hline$M-774-1$ & 500 & $2 n$ & $50 \% \mathrm{Air}+50 \% \mathrm{CO}_{2}$ & 770 & 0.30 \\
\hline$M-774-2$ & 600 & $2 n$ & $50 \% \mathrm{Air}+50 \% \mathrm{CO}_{2}$ & 1350 & 0.22 \\
\hline$M-774-5$ & 800 & $4 \mathrm{~h}$ & $50 \% \mathrm{Air}+50 \% \mathrm{CO}_{2}$ & 1900 & 2.54 \\
\hline$N-774-1$ & 700 & $2 n$ & Air - No Flow & 1650 & 2.19 \\
\hline
\end{tabular}

One photomicrograph from each run has been delivered to ARRADCOM. Particle shape was found to be highly irregular in all runs. Figure 28 shows particles from the penetrator exposure at $5(0)^{\circ}(\text { in air: Fig. } 29 \text {, at } 70)^{\circ} \mathrm{C}$ in air. The particles formed at $500^{\circ} \mathrm{C}$ appear smaller. as was expected from the results previously described in Figs. 23 and 26. Particles in the $1-t 010$ - $\mu \mathrm{m}$ range were usually found, hut most partirles were in the $10-$ to $30-\mu \mathrm{m}$ range. A few needle-like particles as large as $1000 \mu \mathrm{m}$ in length were present. Submicron particles were rare and usually found on the surface of larger particles. The $500^{\circ} \mathrm{C}$ specimens appeared to contain higher populations of small particles than the higher temperature runs. Lamellar structure was found in many part $\mathrm{i}$ cles. particularly in the 700,800 , and $900^{\circ} \mathrm{C}$ photos. Often the lamellae were parallal to the short axis of the particle. A variety of particle shapes appeared to be present lleaf-like. needie. and equiaxial): these could not be characterized in detail by this SEM examination.

\section{SUMMARY AND CONCLUSIONS}

These forced-draft oxidation experiments indicated DU aerosols were dispersed at all temperatures in the range 500 to $1000^{\circ} \mathrm{C}$. An outdoor burning experiment (Burn 4) with peak temperatures near $1100^{\circ} \mathrm{C}$ and broad temperature cycles oxidized $42-47 \%$ of original penetrator weight in $3 \mathrm{~h}$, compared to a maximum of $30 \%$ in $4 \mathrm{~h}$ in the $800^{\circ} \mathrm{C}$ laboratory experiment where a uniform temperature was controlled. Burn 4 also produced more aerosol mass in the respirable size range (up to $62 \%$ of the total aerosol mass was associated with particles under $10-\mu \mathrm{mn} \mathrm{D}_{\text {a }}$. compared to a maximum of $14 \%$ in the laboratory experiments).

Gravimetric analysis of DU metal removed as oxide in the 2-h air-only experiments showed oxidation increased by a factor of approximately three between 600 and $700^{\circ} \mathrm{C}$ to a maximum of $22 \%$ at $700^{\circ} \mathrm{C}$. The 4 -h air- $\mathrm{CO}_{2}$ experiments showed a similar increase started between 600 and $700^{\circ} \mathrm{C}$ and reached a maximum of $30 \%$ at $800^{\circ} \mathrm{C}$. Decreasing oxidation at higher temperatures probably indicated a change in the oxide layer, which tended to protect the penetrator. This general trend of maximum oxidation at 700 or $800^{\circ} \mathrm{C}$ agreed with Megaw results ${ }^{3}$ although these results did not have sufficient detail to show that the maximum rccurred at the beta-gamma transition temperature of $771^{\circ} \mathrm{C}$. as Megaw suggested. 


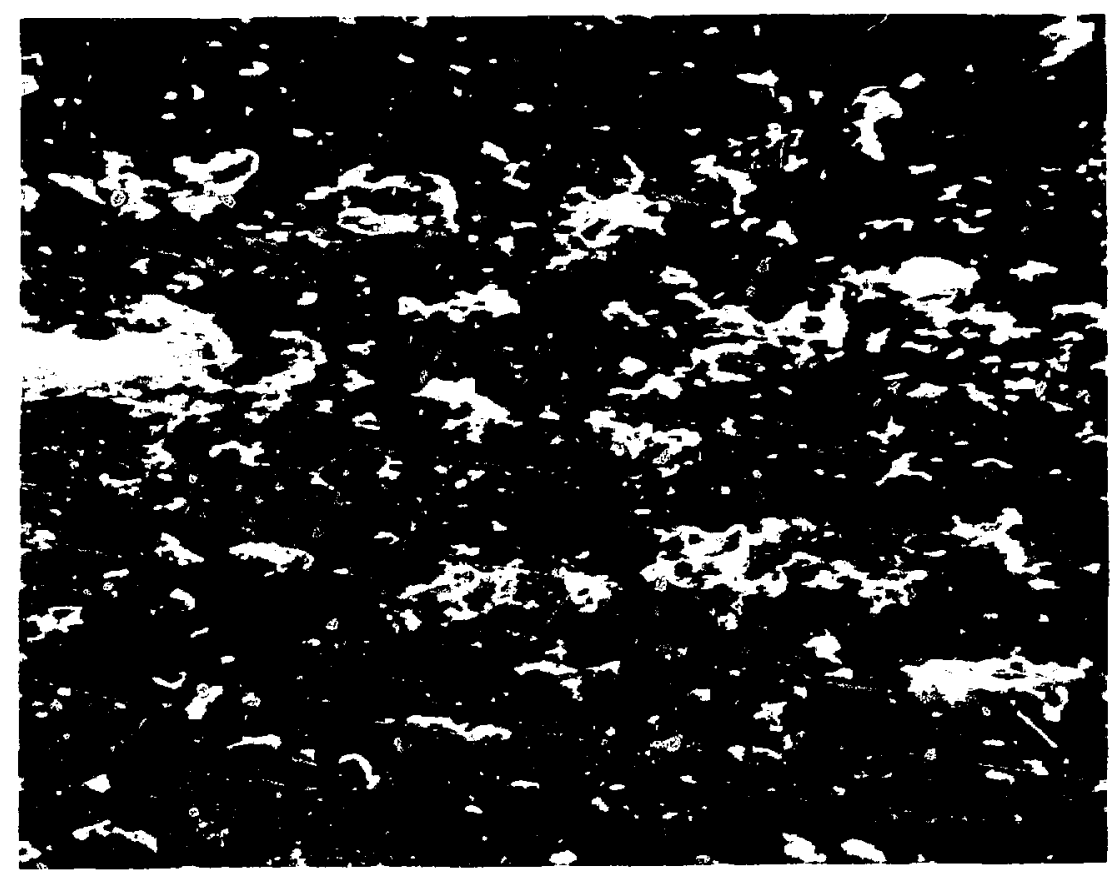

Fig. 28.

Particles from $500^{\circ} \mathrm{C}$ exposure in air.

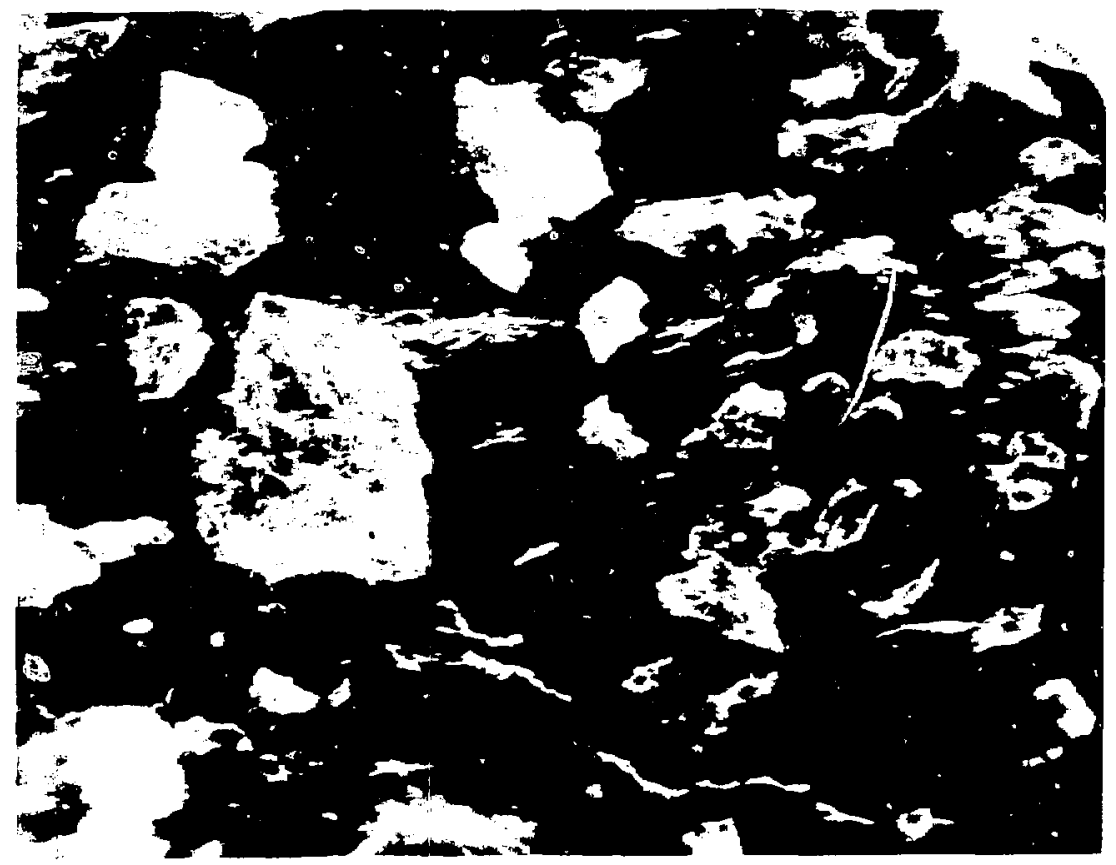

Fig. 29.

Particles from $700^{\circ} \mathrm{C}$ exposure in air. 
Mass median aerodynamic diameter of the DL aeroso! passing the $10-\mu \mathrm{m}$ precutter of the inpactor decreased with increasing temperature from $10 \mu \mathrm{m}$ to $4 \mu \mathrm{m}$. Gec metric standard deviation of these aerosols ranged from 1.7 to 3.6. Mass of aerosol particus $<10-\mu \mathrm{m} D_{\mathrm{se}}$ as percent of peretrator mass ranged from approximately $10^{-3 \%}$ at $500^{\circ} \mathrm{C}$ to $10^{-3 \%}$ at $1000^{\circ} \mathrm{C}$. The effect on aeross: size characteristics of $\mathrm{CO}_{z}$ in the at mosphere was difficult to determine because of the rur: time chante from 2 to $4 \mathrm{~h}$ after the air-only runs were completed.

Nonairborne oxide particles exhibited a decrease in median size $(50 \%$ retained sieve size) between 500 and $600^{\circ} \mathrm{C}$ followed by an increase in size at higher temperatures. This meciian particle size range was approximately $100-600 \mu \mathrm{m}$. The referenced studies ${ }^{2.3}$ both found that particle size increased with increasing temperature.

The particle fraction passing the finest sieve $(<38-\mu \mathrm{m}$ linear dimension) was subjectert to size inaly is by sedimentation technique:s. This analysis indicated that $\mathrm{D}_{\text {a }}$ increased from approximately $35 \% \mathrm{~m}$ at $500^{\circ}\left({ }^{\circ}\right.$ to $6(1)-65 \mu \mathrm{m}$ at $8(0)^{\circ} \mathrm{C}$. The particle size distribution was bimodal in this size range witi the minor mode ge nerally $10-1020-\mu \mathrm{m} \mathrm{D}_{\mathrm{ae}}$. The presence of riajor a mounis of paricles $<10-\mu n_{1} D_{n}$ in this uraction indicates only a small traction of oxide particles of apparently entrainable size actually hecame airborne.

Generai conclusions to be drawn fron these experiments with bare penetiators are as tollow:

(1) $D C$ aerosols with particles in the respirable size range are produced when penetrators are exposed to temperatures abrve $500^{\circ} \mathrm{C}$ for times on the order of one-half bour or more.

(2) Production of the oxide and of aerosol was enhanced by forced-draft and temperature cycl. ing duriag exposure of penetrators under fire conditions.

(3) Penetrators did not exhibit any tendency toward self-sust ained burning. alt hrugh complete oxidation could no doubt he achieved if adequate fuel and time (longer than $1 \mathrm{~h}$ ) were provided.

\section{ACKNOWLEDGMENTS}

Our sincere thanks go to the following perple who contributed significantly to this porject: Ernest Bloore and Ed Wilsey, ARRAIrCOM; Joe (ireene, M-:; Dick Heaton. Hal Ide. Jtan Lindsey. H-5: John Magnuson. (MB-6: Leonard Levinson and John O'Rourke. ('MB-8.

\section{REFERENCES}

1. I. Katz and E. Rahinowitz. The Chemistry of Uranium. p. 165. McGraw-Hill. New York. 1951.

2. L. F. Coleman and L. C. Schwendiman, "Particles Generated During the Air Oxidation of Uraniı n." Hanford Laboratories report HW-SA-2641. August 1962.

3. W. J. Megaw, R. C. Chadwick. A. C. Wells, and J. E. Bridges, "The Oxidation and Release of Iodine-131 From Uranium Slugs Oxidizing in Air and Carbon Dioxide," Reactor Science and Technology (Journal of Nuclear Energy Parts A/B) 15, 176-184 (1961).

4. H. M. Ide, W. D. Jíoss, M. M. Minor, and E. E. Camphell, "Analysis of Uranium in Urine by Delayed Neutrons." Health Phys. 37, 405-408 (1979).

5. ASTM Specification E-11-70, "USA Sieve Series."

6. Commercial Bulletin, "Sedimentation Balance for Automatic Determination of Particle Size Distribution," Sartorius-Werke AG, Gottiagen, West Germany. 
ADDENDUM A

Temperature Chart Records

Burn 4 
TEMPERTUKE HISTORY NF

MIDULF, PENETRATOR

End
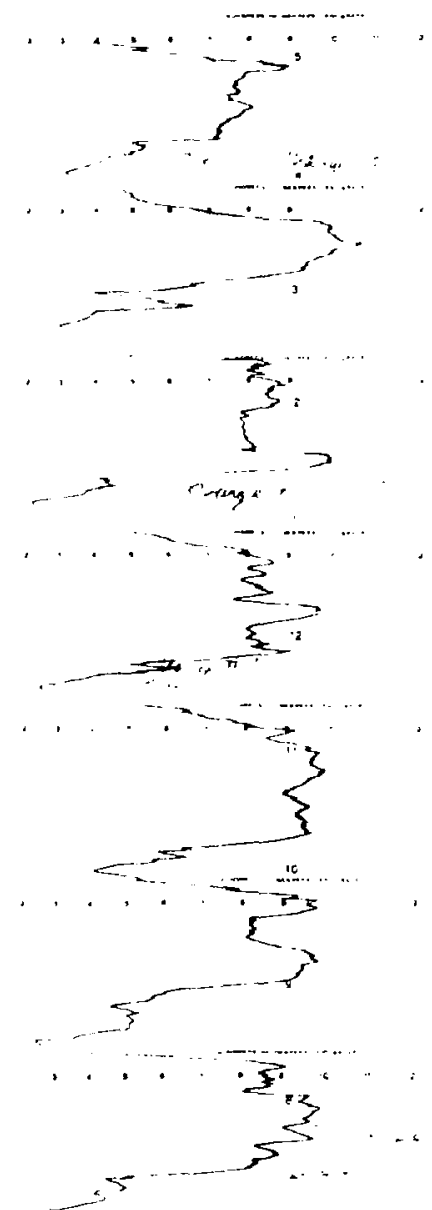

Stort
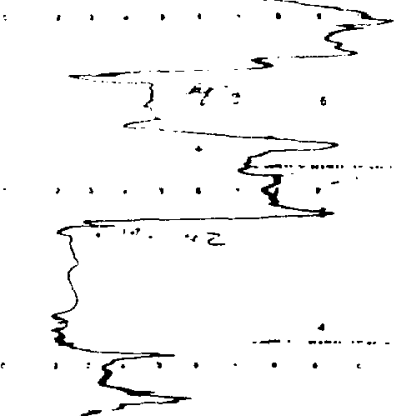

TERPERATURE HISTORY OF

TOP PENETRATOR

End

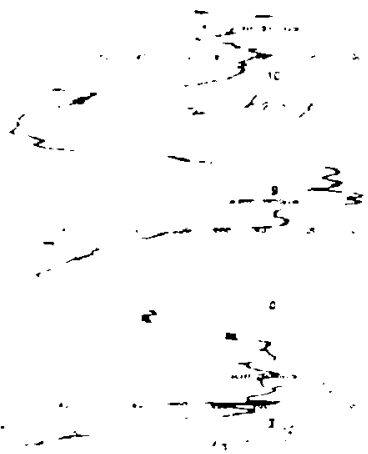

-

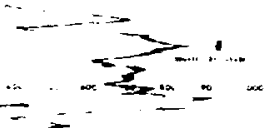

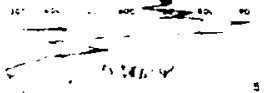
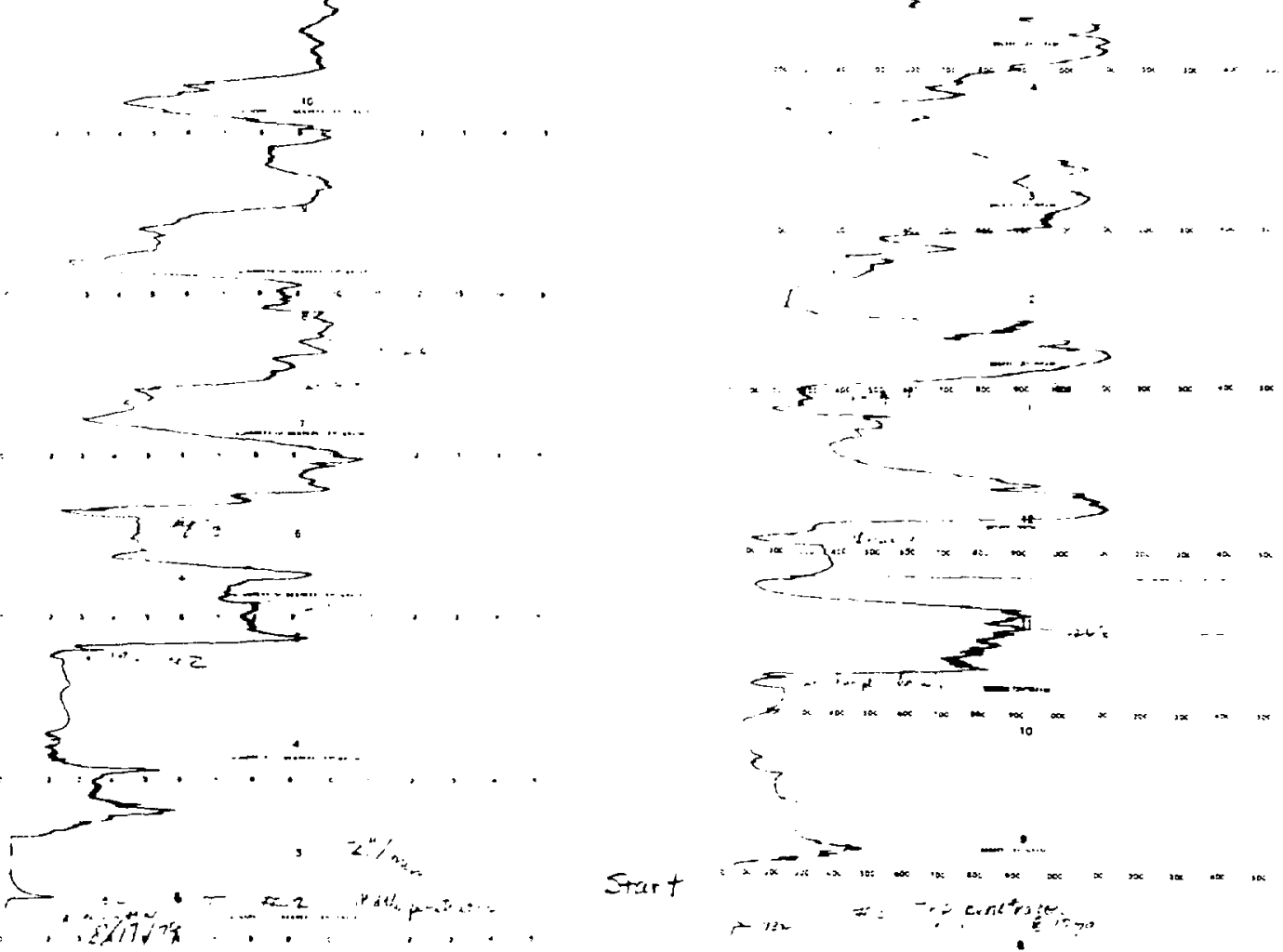


\section{ADDENDUM B}

Sieving Diagrams for Air-Only, $\mathrm{CO}_{2}-\mathrm{Air}$ at $800^{\circ} \mathrm{C}$, and No Flow Runs 


\section{The Tyler Standard Screen Scale}

Cumulative Logarithmic Diagram of Screen Analysis on Sample of $U_{4} f_{-2}+u_{3} O_{f}$

Form No I A mention atoon.

Name Aer Only Dace $8 / .179$

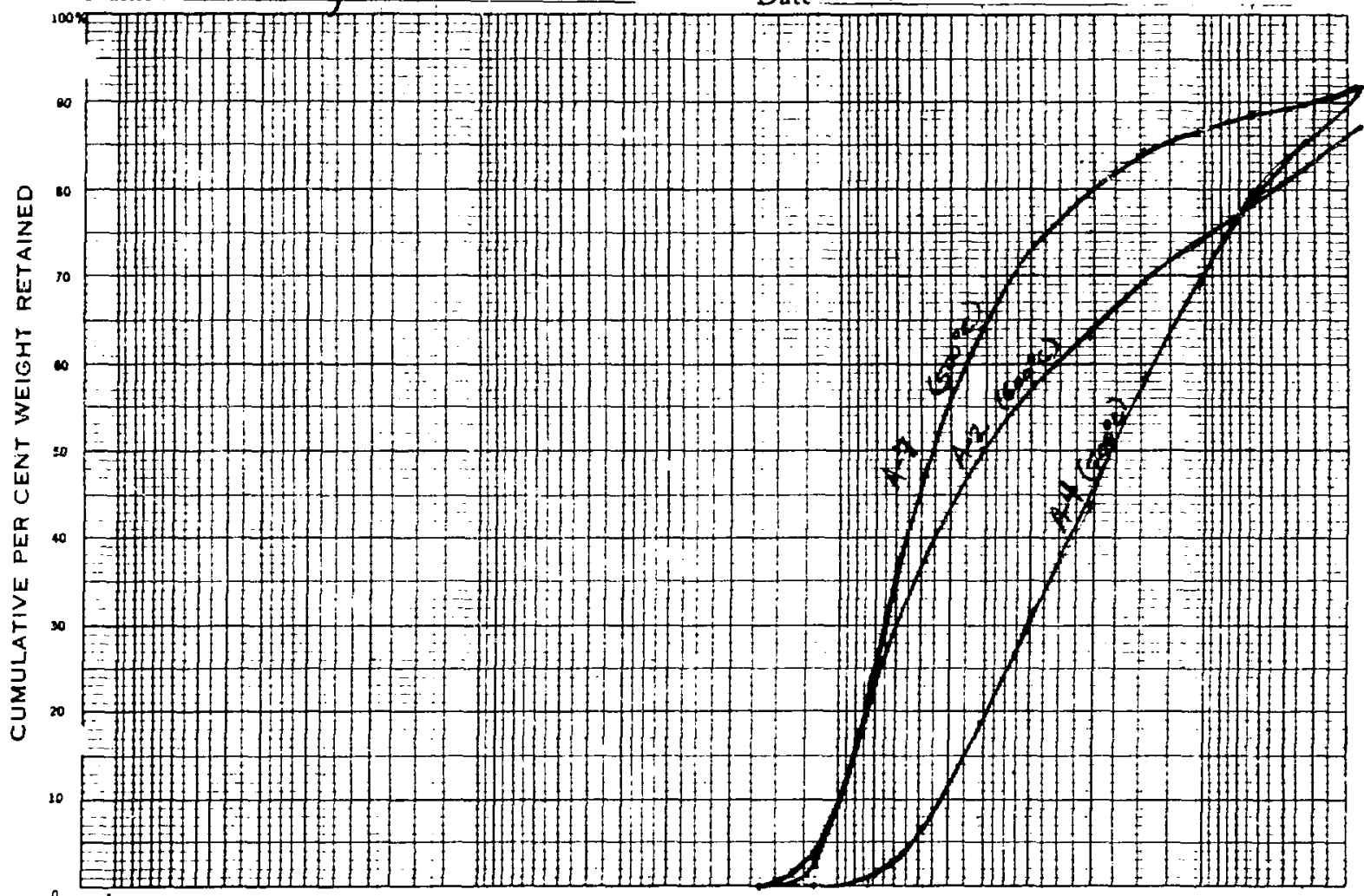

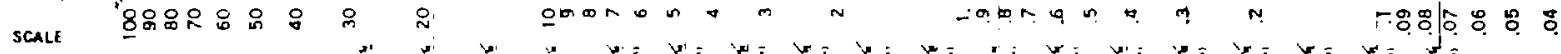

ontur

蓉

\begin{tabular}{|c|c|c|c|c|c|c|c|c|c|c|c|c|c|c|}
\hline & \multicolumn{4}{|c|}{ SCREEM SCALLE RATHO 1.414} & \multicolumn{3}{|c|}{$A-774-7^{(500 x)}$} & \multicolumn{3}{|c|}{$4-774-2^{(6008)}$} & \multicolumn{3}{|c|}{$4-774-4^{(7008)}$} & \\
\hline & \multicolumn{2}{|c|}{ Openings } & \multirow[b]{2}{*}{ 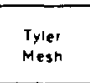 } & \multirow{2}{*}{$\begin{array}{l}\text { U.S. } \\
\text { No. }\end{array}$} & \multirow{2}{*}{$\begin{array}{l}\text { Somole } \\
\text { welents } \\
\end{array}$} & \multirow{2}{*}{ Per cent } & \multirow{2}{*}{ 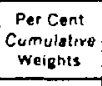 } & \multirow{2}{*}{$\begin{array}{l}\text { Sompie } \\
\text { werghts } \\
\end{array}$} & \multirow{2}{*}{ Pee Cent } & \multirow{2}{*}{$\begin{array}{c}\text { Par Cent } \\
\text { Cumulative } \\
\text { cuetgents } \\
\end{array}$} & \multirow{2}{*}{$\begin{array}{l}\text { Sumple } \\
\text { Weights }\end{array}$} & \multirow{2}{*}{ Por cent } & \multirow{2}{*}{$\begin{array}{c}\text { Per Cent } \\
\text { curumultive } \\
\text { Whaigts }\end{array}$} & \\
\hline & $\begin{array}{l}\text { Minit- } \\
\text { meters }\end{array}$ & ches & & & & & & & & & & & & \\
\hline \multirow{5}{*}{ 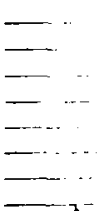 } & \multirow{5}{*}{$\begin{array}{c}26.07 \\
18.85 \\
13.33 \\
0.423 \\
0.080 \\
4.000 \\
3.327 \\
2.382\end{array}$} & \multirow{4}{*}{$\begin{array}{l}1.080 \\
.742 \\
.628 \\
.371 \\
.203 \\
.186\end{array}$} & \multirow{2}{*}{\multicolumn{2}{|c|}{$\begin{array}{c}\text { Fragmants } \\
>\forall \mid 12\end{array}$}} & \multirow{2}{*}{\multicolumn{2}{|c|}{$\cdots-67,4 \mathrm{~g}$}} & \multirow{2}{*}{ 二 } & & \multirow{2}{*}{\multicolumn{2}{|c|}{$157 T_{3}$}} & \multirow{2}{*}{\multicolumn{2}{|c|}{$91.0 \mathrm{~g}$}} & & \\
\hline & & & & & & & & & & & & & & \\
\hline & & & Total & oxide & & & & & 2363 & & & F.Ts & & \\
\hline & & & 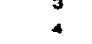 & 4 & & & & & & & & & & \\
\hline & & .131 & - & - & & & - & & 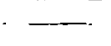 & - & & - & & \\
\hline ON & $\begin{array}{l}2.382 \\
1.081\end{array}$ & $\begin{array}{l}.00 \\
.00\end{array}$ & 10 & 12 & 0.0 & & 0.0 & 00 & 00 & 0.0 & e & e.a & c.e & \\
\hline & & .04 & 14 & 10 & & & 23 & 2.7 & 3.5 & 35 & -0.0 & -20 & e & \\
\hline$\mu$ & .033 & & 20 & 24 & & & 27,9 & 136 & 17.5 & 210 & -0.8 & & & \\
\hline & .880 & $\begin{array}{l}.0232 \\
.0104\end{array}$ & $\begin{array}{l}28 \\
38\end{array}$ & $\begin{array}{l}30 \\
40\end{array}$ & & & $\frac{47.2}{4.0}$ & $\frac{2.7}{9.7}$ & $\frac{17}{126}$ & $\frac{374}{520}$ & $\frac{59}{119}$ & $\frac{5.9}{26}$ & 19 & \\
\hline & .200 & .0110 & 40 & so & & & 23.6 & 60 & $\frac{77}{14}$ & -57 & $\frac{128}{118}$ & ng: & -31 & \\
\hline$\because$ & . 208 & .0032 & $\begin{array}{r}80 \\
100\end{array}$ & $\begin{array}{l}70 \\
100\end{array}$ & & & $\frac{728}{8.3}$ & 42 & 3.9 & $\frac{31}{682}$ & $\operatorname{lin}_{1=0}$ & $\frac{1.8}{151}$ & 525 & \\
\hline n & .94 & & & & & & 65 & 38 & 49 & 32 & 10.5 & 125 & 89 & \\
\hline 争 & $\begin{array}{l}.074 \\
.53\end{array}$ & - & & & & & $\frac{966}{100}$ & 3 & 49 & the & -107 & $\frac{107}{58}$ & & \\
\hline & .032 & & 400 & $\infty$ & & & & 3 & 4. & & 6.2 & 6.2 & & \\
\hline G.5S & .038 & & 400 & 400 & 7.9 & 7.9 & 99.9 & 9.8 & 12.6 & 99.9 & 8.1 & $\Phi$ & 955 & \\
\hline
\end{tabular}


The Tyler Standard Screen Scale

Farm No t,a

Phen ordurios

Cumulative Logarithmic Diagram of Screen Analysis on Sample of Depleted $43_{8}$

Name $50 \%$ Gir $-50 \% \mathrm{CO}_{2}$

Date

$8 / 1 / 79$

L-6

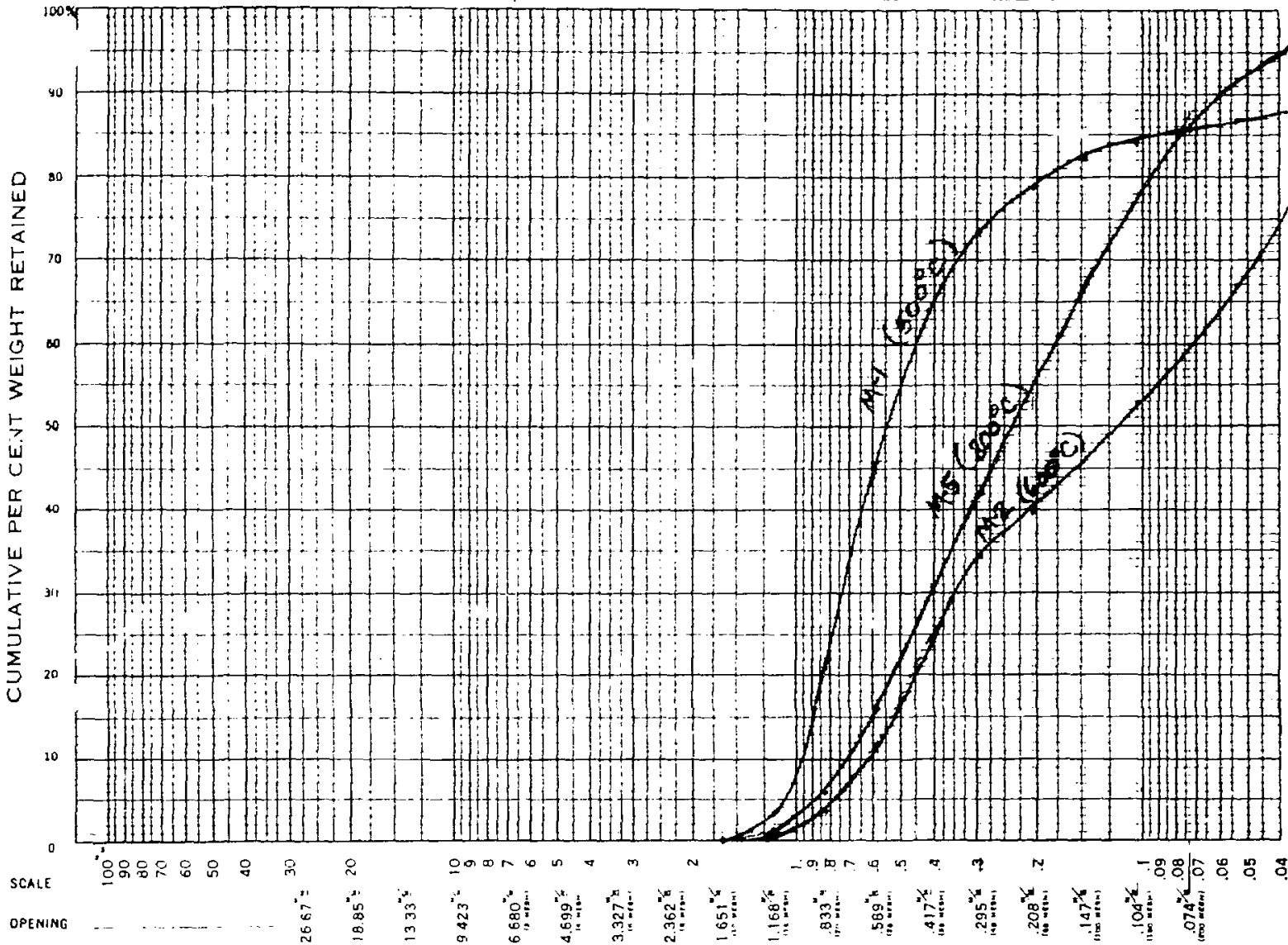

\begin{tabular}{|c|c|c|c|c|c|c|c|c|c|c|c|c|c|c|}
\hline & \multicolumn{4}{|c|}{ SCREEN SCALE RAT1O 1.414} & \multicolumn{3}{|c|}{$M-774-1^{\left(500^{\circ} \mathrm{C}\right.} 2 \mathrm{2b}$} & \multicolumn{6}{|c|}{$M-774-2^{\left(600^{\circ} \mathrm{C}\right)} \mathrm{M}-774-5^{\left(800^{\circ} \mathrm{C}\right)}$} & \\
\hline & $\begin{array}{l}\text { Ope } \\
\text { Millin- } \\
\text { meters }\end{array}$ & $\begin{array}{l}7.5 . \\
\text { Inches }\end{array}$ & $\begin{array}{l}\text { Pyler } \\
\text { Mesh }\end{array}$ & $\begin{array}{l}\text { U. S. } \\
\text { No. }\end{array}$ & $\begin{array}{l}\text { Symore } \\
\text { Welat:s }\end{array}$ & $P_{\mathbf{e}}$ & $\begin{array}{l}\text { Per Cent } \\
\text { Cumulasive } \\
\text { weights } \\
\end{array}$ & $\begin{array}{c}\text { Samo'e } \\
\text { weights }\end{array}$ & nt & $\begin{array}{l}\text { Per Cent } \\
\text { Cumulative } \\
\text { Weights }\end{array}$ & $\begin{array}{l}\text { Samole } \\
\text { welgnts }\end{array}$ & nt & $\begin{array}{c}\text { Per Cent } \\
\text { Cumulatsive } \\
\text { Weignts }\end{array}$ & \\
\hline & 26.87 & 1.050 & Frag & mants & & $946 \mathrm{~g}$ & & & 76.89 & & & 89 & & \\
\hline & 13.33 & $\begin{array}{l}.742 \\
.528\end{array}$ & Total & $\frac{2}{0 x i d e}$ & & 235.19 & 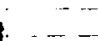 & & $24 \sqrt{2.1}$ & & & $1 / 132$ & & \\
\hline & o & .371 & & & & & & & & & & & & \\
\hline & & & 3 & & $\ldots$ & $\cdots$ & $\ldots$ & - & 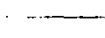 & & & & & \\
\hline & & & 6 & 4 & $\cdots$ & - & $\ldots$ & - & & & & & & \\
\hline & 2.3 & .0 & a & B & & $\cdots$ & -1 & $1-1$ & & & & & & \\
\hline on & 1.8 & .0 & 1 & 12 & 0,0 & 0.0 & 0. & $0 . \overline{0}$ & b. & 0.0 & Q & o. & & \\
\hline & 1.9 & & 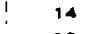 & & & & & $-\frac{0}{3}$ & 7 & 0. & & & & \\
\hline & .8 & .03 & 2 & & 1896 & 78 & 70 & $\frac{3}{3}$ & 7 & 3. & & & & \\
\hline & & & 36 & & $\frac{24.2}{18.2}$ & & & & & & 14 & 14 & & \\
\hline & .2 & .0 & 4 & sc & & 7 & & & 9,9 & & 12.0 & 0 & 42 & \\
\hline & .2 & .00 & B & & & & & & 5. & 39 & & & & $\ldots$ \\
\hline & .11 & .00 & 100 & & & & & I.e & & & & & & \\
\hline & .104 & & 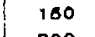 & 30 & 1.8 & 15 & 55 & 16.0 & & 52.9 & & ff & & \\
\hline & 07 & .0028 & & & 10.0 & & & & & & & & & \\
\hline & & & & 7.28 & 7.5 & 1.5 & 87 & 9 & & 26.4 & & & & \\
\hline$s s$ & .038 & & 7200 & Foc & 12.1 & 12. & 100 & 23.6 & 236 & 10 & 4. & & & \\
\hline
\end{tabular}




\section{The Tyler Standard Screen Scale}

Cumulative Jagarithmic Diagram of Screen Analysis on Sample of Depleted $\mathrm{V}_{3} \mathrm{O}_{3} \ldots \ldots$... Name $N=274=$ Air - No flow Date 8.1179

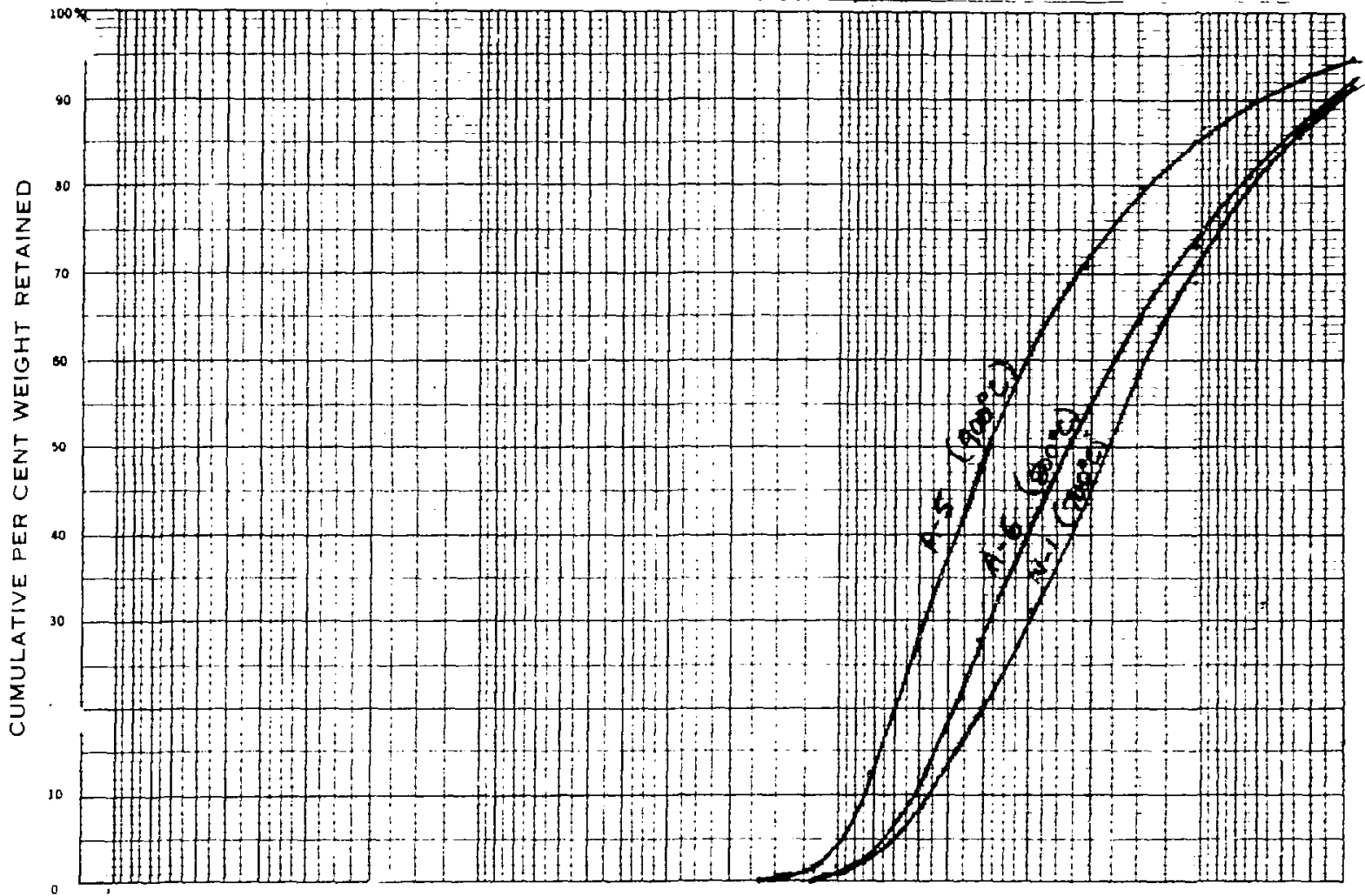

